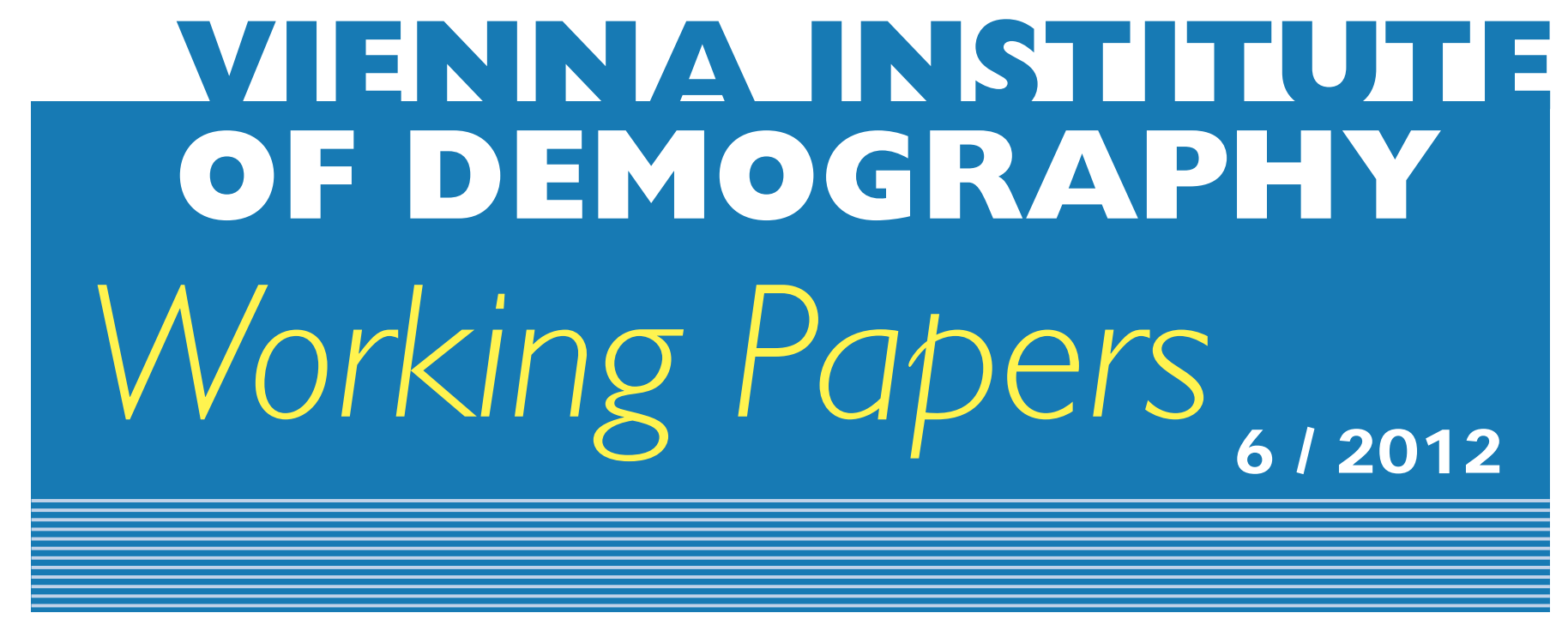

Michael Kuhn and Klaus Prettner

\title{
Growth and Welfare Effects of Health Care in Knowledge Based Economies
}

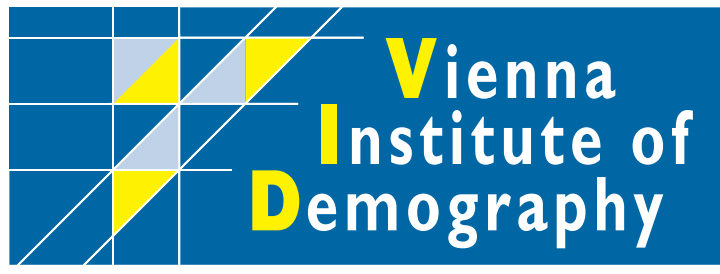

Vienna Institute of Demography Austrian Academy of Sciences

Wohllebengasse 12-I4

A-1040Vienna · Austria

E-Mail:vid@oeaw.ac.at

Website: www.oeaw.ac.at/vid 


\begin{abstract}
We consider an endogenous growth model with Blanchard-Yaari-type overlapping generations that is built around four sectors: final and intermediate goods production, an R\&D sector and a health care sector. Health care serves to lower mortality and morbidity, the latter being related to participation/productivity in the labor market. We show that, regardless of its finance, the impact of health care on economic growth crucially depends on whether or not it increases employment in the R\&D sector. Even if an increasing health care sector reduces the (effective) labor available for production and $R \& D$, it may still fuel $R \& D$ employment and economic growth if the increase in aggregate wealth that comes with expanding longevity raises the capital intensity in the final goods sector to an extent that labor shifts to alternative employment in R\&D. While numerical assessment indicates that the health sectors of the Euro area economies are too large from a growth perspective, we can establish mild conditions under which an expansion of health care beyond the growth-maximizing level constitutes a Pareto-improvement.
\end{abstract}

\title{
Keywords
}

Endogenous growth, mortality, (Blanchard) overlapping generations, health care, research and development, sectoral composition.

JEL classification: I15, I18, O11, O41, O43

\section{Authors}

Michael Kuhn, senior-scientist, Wittgenstein Centre (IIASA, VID, WU), Vienna Institute of Demography, Austria. Email: Michael.kuhn@,oeaw.ac.at.

Klaus Prettner, post-doc researcher, Harvard University, Center for Population and Development Studies, Cambridge. Email: klaus.prettner@wiwi.uni-goettingen.de.

\section{Acknowledgements}

Financial support by the Max Kade Foundation for the post-doctoral fellowship 30393 "Demography and Long-run Economic Growth Perspectives" and by the European Commission under grant SSH-2007-3.1.01-217275 (Long-Run Economic Perspectives of Aging Societies) is gratefully acknowledged. 


\title{
Growth and Welfare Effects of Health Care in Knowledge Based Economies
}

\author{
Michael Kuhn and Klaus Prettner
}

\section{Introduction}

The ongoing debate on health care reform in the United States illustrates the importance of health policy design under both political and economic considerations. While proponents of health care reform typically argue that there are important economic spillover effects of an individuals' health status on the economy, opponents claim that the costs and associated tax increases outweigh the benefits of improved population health. The aim of our paper is to contribute to this debate by formalizing the growth effects of a health care sector that contributes toward lowering mortality and raising productivity and/or labor participation, but also diverts economic resources - in particular labor inputs - away from productive activities.

Economists often argue that health in general and longevity in particular have positive impacts on economic prosperity (see for example Barro, 1997; Shastry and Weil, 2003; Weil, 2007; Lorentzen et al., 2008; Suhrcke and Urban, 2010; Cervellati and Sunde, 2011). The channels through which health is usually deemed to exert its positive influence are summarized in Bloom and Canning (2000) as (i) healthier workers are more productive, (ii) healthier people invest more in human capital which again increases their productivity, (iii) improvements in longevity increase incentives to invest in physical capital and (iv) decreases in mortality can induce a transition to low fertility and thereby create a demographic dividend. The first issue has been analyzed in Bloom and Canning (2005) and Prettner et al. (2012) who show that health is an aspect of human capital of an importance similar to education. The second point has been addressed by e.g. Kalemli-Ozcan et al. (2000) and Cervellati and Sunde (2005), who show that increasing longevity leads to higher educational investments and in turn to faster economic growth. The third point has been most extensively analyzed (see for example Reinhart, 1999; Futagami and Nakajima, 2001; Aísa and Pueyo, 2006; Azomahou et al., 2009; Schneider and Winkler, 2010; Heijdra and Mierau, 2011), where the framework of perpetual growth due to learning-by-doing spillovers according to Romer (1986) is used to show that faster capital accumulation as caused by increases in longevity leads to faster economic growth. The fourth issue has been emphasized by Bloom et al. (2003) who argue that a drop in the fertility rate of a country decreases the overall dependency ratio because it leads youth dependency ratios to decline instantaneously while old age dependency ratios remain unchanged for a sub- 
stantial period of time. In the medium run, this frees parental as well as governmental resources that can then be invested in productive activities. ${ }^{1}$

However, some authors cast doubt on the view that better health, as represented by increasing longevity, substantially increases long-run economic growth (see for example Hazan and Zoabi, 2006; Acemoglu and Johnson, 2007; Hazan, 2009). While Hazan and Zoabi (2006) challenge the view that an increase in parents' life expectancy increases investments in their children's human capital accumulation, Acemoglu and Johnson (2007) argue that there is barely any demographic dividend to be expected from increasing life expectancy because population growth increases substantially in response to decreasing mortality. Furthermore, Hazan (2009) argues that increased life expectancy does not increase lifetime labor supply, implying again a more ambiguous role for health in economic growth.

This discussion illustrates that the interrelations between aging, health and economic growth are complex and by far not completely understood. Our paper aims to shed additional light on another - until now disregarded - channel through which the provision of health care and the resulting improvements in longevity could potentially impact upon long-run economic prosperity namely incentives to invest in research and development $(\mathrm{R} \& \mathrm{D})$. The rationale for doing so is that $\mathrm{R} \& \mathrm{D}$ has been identified as the main driving force of increases in living standards in modern knowledge based economies (see for example Romer, 1990; Grossman and Helpman, 1991; Aghion and Howitt, 1992; Jones, 1995; Kortum, 1997). It has been shown by Prettner (2011) that population aging matters for economic prosperity within these types of growth models. Hence, we base our analysis on an R\&D based endogenous economic growth model of the Romer (1990) type into which we introduce (i) an overlapping generations structure in the vein of Blanchard (1985); and (ii) a labor-intensive health care sector, the output of which improves both survival and productivity/labor participation and is financed by private payments and/or labor income taxes.

In so doing we place particular emphasis on the impact of an expanding health care sector on the other sectors of the economy: R\&D, intermediate goods production and final goods production. Indeed, with an employment share of $8.3 \%$ in the US (May 2012; Bureau of Labor Statistics, 2012) and around 7\% in a number of major EU countries (France, Germany, Sweden, UK; EUROSTAT, 2012) health care constitutes a major industry. Furthermore, in the period 2008-2012 US health care employment has experienced growth rates of around $2 \%$ per annum, as compared to a decline by $-1.1 \%$ per annum in non-health employment (Altarum Institute, 2012). This trend is reflective of a longerterm development reaching back into the 1980s (for additional evidence see Pauly and Saxena, 2012). Against this backdrop, Pauly and Saxena (2012) highlight the importance of understanding the nature of the shift in employment into the health care sector from

\footnotetext{
${ }^{1}$ Lorentzen et al. (2008) investigate empirically the role of (ii)-(iv) as pathways in the relationship between adult mortality and economic growth. Using instrumental variable estimations to account for endogeneity, they find a strong causal effect of adult mortality on growth as well as evidence for channels (ii) and (iv).
} 
other sectors of the economy and its consequences. They raise the question as to "what is the correct story: does medical spending growth divert real labor resources away from more valuable uses into health care, or is health care employment growth, [...], the shining exemplar of high tech job creation? or could both be true?" (quoted from Pauly and Saxena, 2012). They conclude from their empirical analysis of US employment that medical workforce growth was associated with reductions in (relative) employment within manufacturing, construction and information, and with increases in (relative) employment within public administration and other services. When controlling for productivity growth the authors found that the correlation between employment in health care and in manufacturing was significantly reduced which led them to conclude that employment was pushed out of manufacturing (due to increases in productivity) rather than pulled into health care.

Our analysis is suited to explain these structural changes induced by a growing provision of health care. As long as health-related improvements in productivity/participation increase the effective labor force in excess of additional health care employment, the impact on employment in both final goods production and $R \& D$ is unambiguously positive, and so is the impact of health care on economic growth. Interestingly, however, an expansion of the health care sector may stimulate growth even if it requires more effective labor than it is generating. The reason behind this is a shift in employment from final goods production (i.e., manufacturing) into the R\&D sector: As individuals survive longer, they accumulate greater wealth (relative to consumption) which is subsequently converted into capital and machines used for final goods production. With a simultaneous decline in the interest rate, the production of blueprints for new intermediate goods becomes more profitable and labor is pulled into the $R \& D$ sector. At the same time, the increase in capital intensity in final goods production renders this labor available. To the observer a productivity increase pushes out labor from manufacturing while, at the same time, the health care sector is expanding. While our model is therefore largely consistent with the observations by Pauly and Saxena (2012), it suggests the following pathway behind the changes in sectoral employment: To the extent that improvements in longevity lead to an accumulation of additional capital, the provision of health care is actively driving the increase in labor productivity and not only absorbing labor. Moreover, the provision of health care stimulates economic growth to the extent that the labor set free from manufacturing is absorbed by the $R \& D$ sector rather than the medical sector alone. If the health care sector expands beyond a certain threshold, however, it diverts labor from both final goods production and $\mathrm{R} \& \mathrm{D}$ and then stifles economic growth. Indeed, a numerical assessment of our model for the Euro area indicates that their member countries' health sectors are already too large from a growth maximizing point of view.

The ambiguous impact of an expanding health care sector on economic growth appears well in line with the relationship between per capita income growth and the health share (health expenditure as a percentage of GDP) that is depicted in Figure 1. Averaging over the time period 1995 to 2010 the respective data (from World Bank, 2012) for a set of 
180 countries and fitting a quadratic polynomial suggests that economic growth tends to be low for countries with a poorly developed health sector, with the same holding true for countries with a very large health sector. The quadratic shape is robust against the introduction of initial income levels to account for convergence. Countries with a health share roughly the size of 6-7\% of their GDP seem to experience the highest growth rates, which is broadly consistent with (i) our theoretical results of an interior growth maximizing size of the health care sector; (ii) with the numerical implications for the Euro area (see Section 4); and (iii) with empirical evidence on the association between adult mortality and growth (cf. Kelley and Schmidt, 1995; Bhargava et al., 2001). ${ }^{2}$

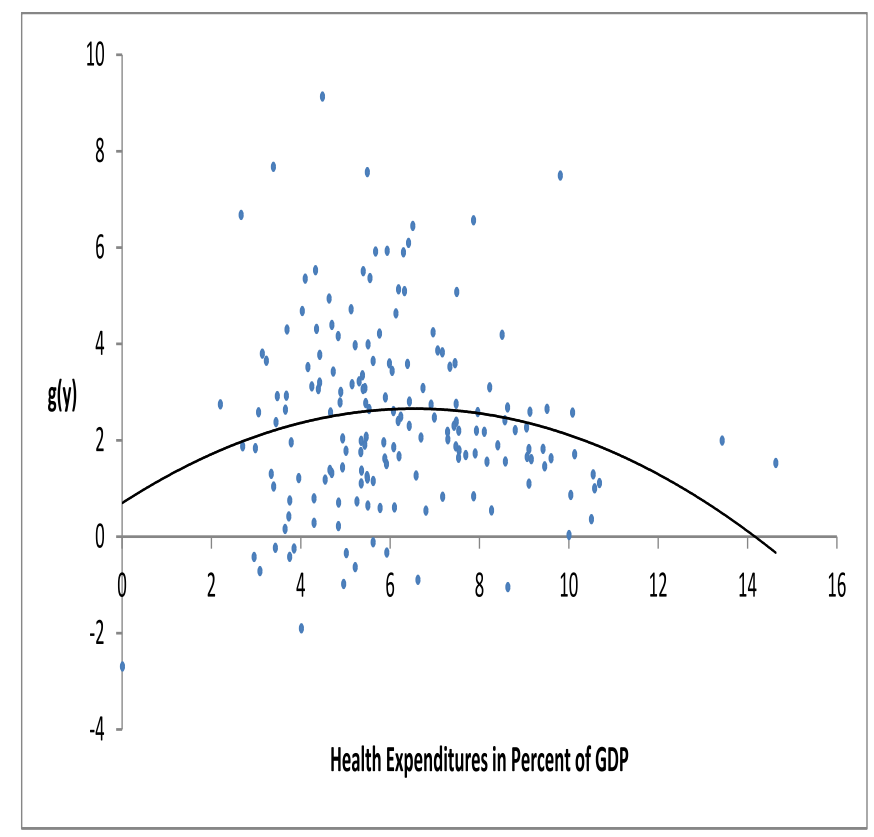

Figure 1: Average growth of per capita GDP versus health share, i.e., health expenditure as percentage of GDP, for 180 countries (1995-2010).

Whether a reduction in economic growth is justified by the benefits of health care ultimately pins down to a value judgment. We show that, within the context of our model, an expansion of health care beyond its growth maximizing level is Pareto optimal under relatively mild conditions. To the extent that a first-order increase in life-cycle utility from lower mortality offsets a second-order loss from a reduction in economic growth, this appears intuitive. However, our analysis shows that the trade-off is more complex and

\footnotetext{
${ }^{2}$ Kelley and Schmidt (1995) find a significant positive cross-effect between the crude death rate and the level of per capita income as explanatory variables for the growth rate of per capita income. Bhargava et al. (2001) identify a significant positive relationship between adult survival rates and growth rates only for low and middle income countries, whereas an insignificant (and weakly negative) relationship holds for high income countries. Reasons for this relationship may lie both in decreasing returns to health production (implying increasing marginal costs of lowering mortality), and in the fact that mortality reductions in high income countries affect to a large extent retirees who no longer contribute toward production. Both factors imply a hump-shaped impact of health provision on economic growth.
} 
Pareto-optimality is by no means a foregone conclusion. First, a reduction in mortality may well imply a reduction in life-cycle consumption as individuals need to stretch their resources over an expanding life-course, and we show that it always does so for old-enough cohorts. This amounts to the familiar trade-off between quantity and quality of life (cf. Murphy and Topel, 2006; Hall and Jones, 2007). A reduction in life-cycle consumption then constitutes a first-order utility-loss which would need to be offset by the direct benefits from extended life-time. We show for the Romer-Blanchard-Yaari setting with logarithmic utility from consumption that all cohorts - those already alive at the point of the 'reform', those who are born at that date, and those yet unborn - benefit (to some degree) from an increase in health care beyond the growth-maximizing level if the maximized growth rate and, thus, the interest rate, are sufficiently high to begin with. In such a case, even if consumption levels fall due to the greater provision of health care, the high rate of initial consumption growth secures an overcompensating benefit from an expansion in life-time. Finally, our consideration of life-cycle utility cohort-by-cohort (akin to Saint-Paul, 1992) allows us to identify those who are least prone to benefit from an increase in health care. It turns out that this is a 'middle-aged' cohort that has accumulated intermediate levels of financial wealth: Individuals from this generation are not yet rich enough and do not yet consume enough to benefit greatly from the expansion of longevity (as older cohorts would); yet at the same time they rely already on financial wealth for supporting their consumption to an extent that they no longer benefit greatly from the boost in life-cycle human wealth coming with a reduction in mortality (as younger cohorts would).

Three articles are related to our approach. Aísa and Pueyo (2004), Aísa and Pueyo (2006) and Schneider and Winkler (2010) also develop a hump-shaped relationship between the provision of health care and endogenous growth within an OLG economy. ${ }^{3}$ In their models, however, growth is driven by capital spillovers a la Romer (1986). This implies that they neglect (a) the role of the $R \& D$ sector for generating knowledge, and (b) the role of endogenous changes in the interest rate, which turn out to be important for the allocation of workers across sectors. Both of these aspects are included in our model as a basis for a deeper and more differentiated explanation of the mechanisms underlying the health-growth nexus.

Aísa and Pueyo (2004) and Aísa and Pueyo (2006) assume that health care is produced from converted consumption/capital goods, while labor is only used in the production of consumption/capital goods. Thus, per se their model does not allow to trace the striking change in employment shares identified by Pauly and Saxena (2012). ${ }^{4}$ The set-up

\footnotetext{
${ }^{3}$ van Zon and Muysken (2001) consider health production within the endogenous growth model by Lucas (1988). Similar to our model, the health care sector competes for labor with the final goods sector and the human capital sector. While van Zon and Muysken (2001) also find a hump-shaped relationship between health care and economic growth. However, as they consider the planner solution for a representative agent economy, the transmission channels are yet again very different.

${ }^{4}$ For reasons of analytical tractability, Aísa and Pueyo (2004) and Aísa and Pueyo (2006) need to assume that the mortality rate decreases in the level of health care (or equivalently health expenditure) per unit of $G D P$. This has the awkward implication that for a given level of health care inputs, mortality increases in the level of GDP, a relationship that contradicts most empirical evidence (e.g. Filmer and Pritchett, 1999;
} 
in Schneider and Winkler (2010) is closer to ours in that health care competes for labor with final goods production. Nonetheless, the neglect of an R\&D sector in the underlying Romer (1986) framework and the direct trade-off between employment in health care or in final goods production implies rather different results. In their baseline model Schneider and Winkler (2010) scale the spillover in a way that the size of the labor input in final goods production is immaterial. In this case, health care has an unambiguously positive impact on economic growth, as improved survival lowers the consumption-capital ratio and, thereby, enhances economic growth without any offsetting impact through the allocation of labor. In an extension Schneider and Winkler (2010) allow for a negative impact of health care employment on employment in the final goods sector. While this leads to the expected hump-shaped relationship between health care and economic growth, the specification implies yet again a different channel of transmission. In particular, in Schneider and Winkler (2010) a reduction in final goods employment is a necessary condition for a negative impact of health care on economic growth. In contrast, in our set-up a reduction in final goods employment contributes toward economic growth as long as it enhances R\&D employment.

A second aspect that is not properly picked up by the models based on Romer (1986) is the endogeneity of the interest rate. This is out of line with recent economic-demographic modeling which typically allows for a response in the interest rate to demographic aging within a closed economy or to differential aging within an open economy. Indeed, the calibrated OLG models by e.g. Miles (1999), Attanasio et al. (2007) and Krueger and Ludwig (2007) predict a considerable reduction in the (world) interest rate due to aging in industrialized countries. As it turns out in our model the reduction in the interest rate due to the greater accumulation of wealth and capital by an aging population is indeed the crucial force behind the reallocation of labor from final goods production to the R\&D sector; and, thus, a factor in the enhancement of growth that remains unaccounted for in Aísa and Pueyo (2004), Aísa and Pueyo (2006) and Schneider and Winkler (2010).

Finally, we consider the welfare implications of expanding health care beyond its growth-maximizing levels. While Aísa and Pueyo (2004) and Aísa and Pueyo (2006) do not consider the optimality of health care at all, Schneider and Winkler (2010) focus on the individually optimal choice of health care. Our focus is different in that we examine how a small increase in the provision of health care beyond its growth-maximizing level affects the life-cycle utility of different cohorts. ${ }^{5}$ In so doing, we assess the Pareto-optimality of a health care reform. Again, the reduction of the interest rate in response to an increase in longevity turns out to be important: Lower interest rates imply less individual saving and, therefore, less scope for growth in individual consumption. As it turns out this effect is compromising Pareto-optimality and needs to be compensated by a sufficient growth rate to begin with.

The paper proceeds as follows: Section 2 develops a model of endogenous economic Cutler et al., 2006).

${ }^{5}$ For a similar analysis regarding the effects of changes in taxation see, e.g., Saint-Paul (1992). 
growth with demography and a health care sector financed by a mix of private payments and a tax on labor income. Section 3 examines in detail the impact of a variation in the size of the health care sector on long-run economic growth, the results being numerically illustrated for the Euro area in Section 4. The welfare analysis is provided in Section 5 , and the concluding Section 6 points out policy implications, limitations and scope for future work.

\section{The Model}

In this section we describe the structure of the model, placing particular emphasis on its demographics properties, the role of health care, and the sectoral composition of the economy. We derive aggregate laws of motion for capital and consumption and solve for the long-run economic growth rate along a balanced growth path.

\subsection{Basic Assumptions: Sectoral Set-up and Demography}

The basic structure of our model follows Prettner (2011) who integrates an overlapping generations structure in the spirit of Blanchard (1985) into a Romer (1990) model of endogenous economic growth driven by purposeful R\&D investments. The model economy is assumed to consist of four sectors: final goods production, intermediate goods production, R\&D and health care. Altogether there are two productive factors that can be used in these four sectors: capital and labor. Labor (in the form of workers) and machines are used to produce final goods in a perfectly competitive market; capital and blueprints are used in the Dixit and Stiglitz (1977) monopolistically competitive intermediate goods sector to produce machines; labor (in the form of scientists) is used to produce blueprints in the perfectly competitive R\&D sector; and, finally, labor (in the form of doctors and nurses) is used in the health sector to generate improvements in both longevity and labor force participation and/or productivity.

Our model economy exhibits the following demographic properties: We assume that the total population is composed of different cohorts that can be distinguished by their date of birth $t_{0}$. Each cohort consists of a measure $N\left(t_{0}, t\right)$ of individuals at a certain point in time $t>t_{0}$. In line with Blanchard (1985) we assume that individuals face a constant risk of death at each instant which we denote by $\mu$. Due to the law of large numbers this rate is equal to the fraction of the population dying at each instant. To fit the Romer (1990) case, we assume that the population does not grow and hence that the birth rate (being equivalent to the period fertility rate in such a setting) equals $\mu .^{6}$

\footnotetext{
${ }^{6}$ In the presence of population growth there would not be a long-run balanced growth path in the Romer (1990) framework. Instead, we would have to use a semi-endogenous growth model in the spirit of Jones (1995) as baseline framework. Doing so, however, would lead to the unrealistic (and from a modeling perspective uninteresting) situation where only the positive growth effect of decreasing mortality is present in the long run (through its impact upon the population growth rate), while the negative influences of increases in taxes to finance health care (and thereby increases in the amount of labor used in the health sector and decreases in the amount of labor used in the R\&D sector) would vanish. Therefore we rely
} 
Note that while reductions in the mortality rate, afforded by increasing levels of health care, imply proportional reductions in the birth rate, this amounts to an accounting effect rather than to changes in fertility decisions. As we show in Appendix A.1 for a constant cohort fertility rate, i.e., a constant number of children over the life-course, a decrease in mortality must imply a one-to-one decrease in period fertility. With increasing longevity, individuals spread a constant number of births (for a constant single-sex population, indeed, a single birth) over a longer life-course. Statistically, this implies that fewer children are born at each point in time and thus a lower birth rate. Indeed, this corresponds well with the evidence compiled by demographers that the decline in period fertility rates observed over the past decades does not necessarily imply a reduction in cohort fertility but may rather be the effect of fertility postponement over a life-course of increasing duration (see e.g., Bongaarts and Feeney, 1998; Bongaarts and Sobotka, 2012).

\subsection{Consumption}

Suppressing time subscripts, an individual belonging to the cohort born at $t_{0}$ maximizes her discounted stream of lifetime utility

$$
U=\int_{t_{0}}^{\infty} e^{-(\rho+\mu)\left(s-t_{0}\right)} \log (c) d s,
$$

where the mortality rate $\mu \geq 0$ augments the subjective time discount rate $\rho>0$. Period utility $\log (c)$ is derived from individual consumption, $c$, of the final good, the production of which is described in Section 2.5. Individuals earn income from life-insured assets, from the supply of their labor, and from dividends paid out by the intermediate goods sector. Individuals do not receive and do not leave bequests. For the sake of a comprehensive exposition we follow Yaari (1965) and assume a perfect annuity market on which individuals can insure themselves against the risk of dying with positive assets. The government levies a tax on labor income, which is tantamount to social security contributions. In Subsection 2.4 we show how this tax is then used to finance the public share of health care. Individuals spend their income on consumption and for the purchase of private health care. Consequently, the wealth constraint of an individual reads

$$
\dot{k}=(r+\mu-\delta) k+(1-\tau) w \ell+d-c-p_{H} \sigma h
$$

where $k$ refers to the individual capital stock; $r$ is the rental rate of capital; $\delta \geq 0$ is the rate of depreciation; $w \ell$ is the individual's (annual) wage income, with $w$ the wage rate and $\ell$ the individual's inelastic annual labor supply; $\tau \in[0,1]$ is the tax rate on labor income; $d$ is the income from dividends (net of new investments) in the intermediate goods sector; $c$ is consumption expenditure with the price normalized to one; and $p_{H} \sigma h$ are private health

on the more realistic model structure outlined here and note that a similar mechanism as the one we describe would hold in the transition phase of semi-endogenous growth models. This could be illustrated numerically which is not desired within the confines of this paper but on top of our future research agenda. 
care payments, with $p_{H}$ the unit price, $h$ the overall quantity of health care, and $\sigma \in[0,1]$ the share of private finance. Utility maximization subject to the wealth constraint yields the following standard Euler equation (for a derivation see Appendix A.2)

$$
\frac{\dot{c}}{c}=r-\rho-\delta,
$$

stating that consumption grows if and only if the real rate of return on capital exceeds the sum of the subjective time discount rate and the rate of capital depreciation.

\subsection{Aggregate Capital Stock and Aggregate Consumption}

In our framework, agents are heterogeneous with respect to accumulated wealth, as older agents have had more time to build up positive assets. In order to obtain the law of motion for aggregate capital and the economy-wide ("aggregate") Euler equation, we apply the following aggregation rules across all cohorts alive at time $t$ (cf. Heijdra and van der Ploeg, 2002):

$$
\begin{aligned}
K(t) & \equiv \int_{-\infty}^{t} k\left(t_{0}, t\right) N\left(t_{0}, t\right) d t_{0}, \\
C(t) & \equiv \int_{-\infty}^{t} c\left(t_{0}, t\right) N\left(t_{0}, t\right) d t_{0} .
\end{aligned}
$$

By applying our demographic assumptions we can rewrite these rules as

$$
\begin{aligned}
C(t) & \equiv \mu N \int_{-\infty}^{t} c\left(t_{0}, t\right) e^{\mu\left(t_{0}-t\right)} d t_{0}, \\
K(t) & \equiv \mu N \int_{-\infty}^{t} k\left(t_{0}, t\right) e^{\mu\left(t_{0}-t\right)} d t_{0}
\end{aligned}
$$

because for a constant population each cohort is of size $\mu N e^{\mu\left(t_{0}-t\right)}$ at a certain point in time $t>t_{0}$.

Carrying out the calculations described in Appendix A.3 we arrive at the following expressions for the law of motion of aggregate capital and for the aggregate Euler equation

$$
\begin{aligned}
\dot{K} & =(r-\delta) K(t)-C(t)+(1-\tau) W(t)+D(t)-p_{H} \sigma H \\
\frac{\dot{C}(t)}{C(t)} & =r-\rho-\delta-\mu(\rho+\mu) \frac{K(t)}{C(t)}
\end{aligned}
$$

where $W(t), D(t)$ and $H$, respectively, describe aggregate labor income, aggregate (net) dividends, and aggregate consumption of health care. ${ }^{7}$ Note that the aggregate Euler equation differs from the individual Euler equation by the term $\mu(\rho+\mu) K(t) / C(t)$. This term is correcting for the turnover of generations and basically takes into account that older individuals, who are wealthier and who can therefore afford more consumption, are

\footnotetext{
${ }^{7}$ Aggregate dividends and health care payments are further characterized in Appendix A.5.
} 
constantly replaced by newborns without capital holdings who cannot afford that much consumption. This process slows down aggregate consumption growth as compared to individual consumption growth.

\subsection{Health Care}

Following Schneider and Winkler (2010) we assume for the health care sector that labor is converted into health care according to the following production function

$$
h N=L_{H},
$$

where $L_{H}$ is aggregate employment in the health care sector, $h$ is health care per capita, and $N$ denotes the size of the population. Thus, the consumption of health care per capita, $h=L_{H} / N$ increases with the employment in the health care sector per capita. Here, we note that the constraints $L_{H} \leq L \leq N$ with $L$ being the size of the available labor force place some upper bound $h_{\max }=L / N \leq 1$ on the per capita consumption of health care. Intuitively, the provision of health care cannot be expanded beyond the point at which the total labor force is employed in the health care sector. The mortality rate $\mu(h)$ is decreasing in the (annual) level of health care per capita, $h$. Specifically, we assume

$$
\begin{aligned}
\mu(0) & =\bar{\mu} \in(0, \infty), \quad \mu\left(h_{\max }\right)=\mu \in[0, \bar{\mu}), \\
\mu^{\prime} & \leq 0, \quad \mu^{\prime \prime} \geq 0, \quad \mu^{\prime \prime \prime} \leq 0
\end{aligned}
$$

implying that health care lowers mortality from a maximum $\bar{\mu}$ to some minimum $\underline{\mu} \geq 0$, corresponding to the maximum feasible level of health care $h_{\max }$ at which all available labor is employed in the health care sector. ${ }^{8}$ We assume health care to be subject to (weakly) diminishing returns. Apart from lowering mortality, health care also contributes to a reduction in morbidity, which in our context allows individuals to increase their effective labor supply per annum, $\ell(h) .{ }^{9}$ Specifically, we assume

$$
\begin{aligned}
0 & \leq \ell(0) \leq \ell\left(h_{\max }\right)=h_{\max } \leq 1 \\
\ell^{\prime} & \geq 0, \quad \ell^{\prime \prime} \leq 0, \quad \ell^{\prime \prime \prime} \geq 0
\end{aligned}
$$

Thus, the labor supply per capita increases in the level of health care at (weakly) decreasing returns. Assuming that individuals supply the same amount of labor regardless of their

\footnotetext{
${ }^{8}$ For empirical evidence on the impact of health care on mortality see e.g. Cremieux et al. (1999), Filmer and Pritchett (1999), Berger and Messer (2002), Thornton (2002), Lichtenberg (2004) and Cutler et al. (2006).

${ }^{9}$ Healthier individuals provide more labor (per annum) and/or are more productive. See Rivera and Currais (2004) for some evidence that current public health care spending has a positive impact on labor productivity.
} 
age $^{10}$ we can write total labor supply as ${ }^{11}$

$$
L=\ell(h) N
$$

It is then easy to verify that the constraint $L_{H} \leq L \leq N$ implies $h \leq \ell(h) \leq \ell\left(h_{\max }\right)=$ $h_{\max } \leq 1 .^{12}$

Finally, consider the finance of health care. With $\sigma \in[0,1]$ denoting the share of private finance in health care, the public share $1-\sigma$ is financed by a tax on labor income that is tantamount to a social security contribution. Altogether, this implies that aggregate health expenditure, $G$, satisfies

$$
w L_{H}=G=p_{H} \sigma H+\tau W
$$

where the equation on the LHS measures the expenditure on health care $w L_{H}=w h N$, while the equation on the RHS measures the composition of health care finance, with $p_{H} \sigma H=p_{H} \sigma h N$ the amount of private finance and $\tau W=\tau w \ell(h) N$ the tax income. For the sake of a concise exposition we assume here that the public health care budget is balanced at each instant. ${ }^{13}$ Assuming perfect competition within the health care sector, we have that $p_{H}=w$, implying that we can rewrite the outer equalities in (13) to $h=$ $\sigma h+\tau \ell(h)$, which solves for a tax rate $\tau=(1-\sigma) h / \ell(h) \in[0,1]$. As expected, the tax is increasing in the provision of health care per capita, $h$, and in the share $1-\sigma$ that is financed publicly, but at the same time it is falling in the per capita supply of labor. Having, thus, noted the financing mechanism, it will become evident in the course of analysis that under our assumptions of (i) a competitive health care sector and (ii) a non-distortionary tax, the mode of health care finance has no implications for economic growth. Indeed the latter is only determined by the size of the health care sector, as measured by $h$.

\subsection{Production}

The production side of the economy closely follows Romer (1990). Final goods $Y$, representing both consumption goods and (undifferentiated) capital inputs into the production of intermediate goods, are produced according to

$$
Y=L_{Y}^{1-\alpha} \int_{0}^{A} x_{i}^{\alpha} d i
$$

\footnotetext{
${ }^{10}$ This assumption is consistent with the assumption of an age-independent mortality rate.

${ }^{11}$ Naturally, at aggregate level $\ell(h)$ can be also interpreted as the share of the population that is able to work a full time equivalent or as the average time at work, where individuals may differ in their labor supply depending on whether or not they are healthy or sick.

${ }^{12}$ If $\ell(h)$ is a measure of productivity rather than participation, it is conceivable that $\ell\left(h_{\max }\right)=h_{\max }>1$. We disregard this case without loss of generality.

${ }^{13}$ Relaxing this assumption would not change our results qualitatively.
} 
where $L_{Y}$ refers to labor used in final goods production, $A$ is the technological frontier, i.e., the "number" of differentiated machines available, $x_{i}$ is a measure of the quantity of type- $i$ machines used in final goods production, and $\alpha \in[0,1]$ is the factor share of intermediate inputs. Note that output of the final goods sector is equivalent to the GDP of a country. Profit maximization and the assumption of perfect competition in the final goods sector imply that factors are paid their marginal products such that

$$
\begin{aligned}
w_{Y} & =(1-\alpha) \frac{Y}{L_{Y}} \\
p_{i} & =\alpha L_{Y}^{1-\alpha} x_{i}^{\alpha-1}
\end{aligned}
$$

where $w_{Y}$ refers to the wage rate paid in the final goods sector and $p_{i}$ to prices paid for intermediate inputs.

The intermediate goods sector is monopolistically competitive in the spirit of Dixit and Stiglitz (1977). After an intermediate goods producer has purchased a blueprint, it can transform one unit of capital into one unit of the intermediate good, implying $x_{i}=k_{i}$. Maximizing operating profits $\pi_{i}=\left(p_{i}-r\right) k_{i}=\alpha L_{y}^{1-\alpha} k_{i}^{\alpha}-r k_{i}$ yields prices of machines

$$
p_{i}=\frac{r}{\alpha},
$$

where $1 / \alpha$ is the markup over marginal costs (cf. Dixit and Stiglitz, 1977). Note that due to symmetry we can now drop the index $i$. The aggregate capital stock is then equal to the total quantity of intermediates, i.e., $K=A x$, and aggregate production becomes

$$
Y=\left(A L_{Y}\right)^{1-\alpha} K^{\alpha}
$$

implying that technological progress is labor augmenting.

Similar to the central building block of the Romer (1990) model, the R\&D sector employs scientists to discover new blueprints. Depending on their number, $L_{A}$, and their productivity, $\lambda$, the production of blueprints evolves according to

$$
\dot{A}=\lambda A L_{A}
$$

Under perfect competition R\&D firms maximize profits $\pi_{A}=p_{A} \lambda A L_{A}-w_{A} L_{A}$, with $p_{A}$ representing the price of a blueprint. The first order condition pins down wages in the research sector to

$$
w_{A}=p_{A} \lambda A
$$

We immediately see that wages of scientists increase with the price for blueprints $p_{A}$, with research productivity $\lambda$, and with an expanding technological frontier $A$. The first two factors also increase wages of scientists in relation to wages of workers in final goods production and health care and hence they render $\mathrm{R} \& \mathrm{D}$ employment relatively more attractive. Increases in the technological frontier, however, raise wages in all three labor- 
employing sectors alike and consequently do not change the relative attractiveness of R\&D employment.

\subsection{Market Clearing and Steady-state Growth}

Perfect labor mobility leads to an equalization of wages across those sectors that employ labor: R\&D, final goods, and health care. We can therefore insert (15) into (20) to obtain the equilibrium condition

$$
p_{A} \lambda A=(1-\alpha) \frac{Y}{L_{Y}} .
$$

Under free entry into the intermediate goods sector, firms in the R\&D sector can charge prices of blueprints that are equal to the present value of operating profits in the intermediate goods sector because there is always a potential entrant willing to outbid any lower price. We then have

$$
p_{A}=\int_{t}^{\infty} e^{-R(t, \tau)} \pi d \tau
$$

where $R(t, \tau)=\int_{t}^{\tau}(r(s)-\delta) d s$, i.e., the discount rate is the market interest rate paid for household savings. Via the Leibniz rule and the fact that prices of blueprints do not change along a balanced growth path, we obtain

$$
p_{A}=\frac{\pi}{r-\delta}
$$

Using the expression of operating profits and (23) we can derive prices for blueprints as (see Appendix A.4)

$$
p_{A}=\frac{(1-\alpha) \alpha Y}{(r-\delta) A}
$$

Note that a higher interest rate, $r-\delta$, reduces the price for a blueprint because it decreases the present value of operating profits in the intermediate goods sector. Assuming that labor markets clear, i.e., $L=L_{A}+L_{Y}+L_{H}$, where $L=\ell(h) N$ is aggregate labor supply and where $L_{H}=h N$ is the employment in the health sector, we can then determine employment in the final goods sector and in the R\&D sector, respectively, by using (21) and $(24)^{14}$

$$
\begin{aligned}
& L_{Y}=\frac{r-\delta}{\alpha \lambda}, \\
& L_{A}=\max \left\{[\ell(h)-h] N-\frac{r-\delta}{\alpha \lambda}, 0\right\} .
\end{aligned}
$$

These two equations imply first that a decrease in the interest rate raises the number of scientists and decreases the number of workers in the final goods sector. This is because a lower interest rate drives up the price of a blueprint $p_{A}$ [see (24)] and, thus, the wages

\footnotetext{
${ }^{14}$ It can be verified from the equilibrium dynamics (29) and (30) that $r \geq \delta$ and, therefore, $L_{Y} \geq 0$ must be true: Suppose otherwise, then (29) implies $g<0$, whereas (30) implies $g>0$ and, thus, a contradiction. By contrast, $L_{A} \geq 0$ is not always guaranteed. For instance, $\bar{h}=\ell(\bar{h})$ would trigger negative $\mathrm{R} \& \mathrm{D}$ employment, $L_{A}<0$, which, of course, is not feasible.
} 
of scientists [see (20)]. Second, an increase in the productivity of scientists $\lambda$ raises their wages relative to those in the final goods sector and thus induces labor to move from final goods production into R\&D. Third, an increase in the elasticity of intermediates in final goods production, $\alpha$, reduces the number of workers needed in the final goods sector and thus tends to push employment toward the R\&D sector. Fourth, an increase in the size of the labor force $N$ raises the number of scientists. Fifth, an increase in health care directly raises the workforce available for $\mathrm{R} \& \mathrm{D}$ and/or production if and only if $\ell^{\prime}>1$, i.e., if and only if participation in the labor market (or per-capita supply of labor) grows by more than one: Intuitively, the available labor force increases if for each worker switching into the health care sector more than one (effective) workers can enter the work force due to improvements in health.

Inserting (26) into (19) leads to the growth rate of the technological frontier

$$
g=\frac{\dot{A}}{A}=\lambda L_{A}=\max \left\{\lambda[\ell(h)-h] N-\frac{r-\delta}{\alpha}, 0\right\}
$$

where the implied non-negativity constraint on the growth rate follows as R\&D employment cannot be negative. Along a balanced growth path we know that $\dot{Y} / Y=\dot{C} / C=$ $\dot{K} / K=\dot{A} / A$, so that $g$ also denotes the growth rate of output, consumption and capital. ${ }^{15}$

\section{The Growth Impact of Health Care}

In this section we analyze the impact of the health care sector on the balanced growth path of an economy. Recall from Subsection 2.4 that health care per capita is given by $h=L_{H} / N$ where $h \in\left[0, h_{\max }\right]$ with $h_{\max }=\ell\left(h_{\max }\right)$. For a closed economy capital accumulation can be expressed as $K=Y-C-\delta K$, i.e., total output of the final good is either consumed or invested, with capital accumulation following as the investment net of replacements due to depreciation (see also Appendix A.5). The dynamic system describing our economy can then be written as

$$
\begin{aligned}
g & =\frac{r}{\alpha^{2}}-\xi-\delta, \\
g & =r-\rho-\delta-\frac{\mu(h)[\rho+\mu(h)]}{\xi}, \\
g & =\max \left\{\lambda[\ell(h)-h] N-\frac{r-\delta}{\alpha}, 0\right\},
\end{aligned}
$$

where we define $\xi:=C / K$ and note that $Y / K=r / \alpha^{2}$ (see Appendix A.4). The dynamics are thus described by capital accumulation as in (28), by the Euler equation as in (29), and by the growth of $\mathrm{R} \& \mathrm{D}$ output as in (30). The equations determine the interest rate $r$, the consumption-capital ratio $\xi$ and the economic growth rate $g$. Health care directly affects the system through changes in the mortality rate, and, thus, in the generational

\footnotetext{
${ }^{15}$ Note that since population growth is zero, per capita output, per capita consumption, per capita capital and aggregate wages also grow at rate $g$.
} 
turnover and through changes in the workforce available for $R \& D$. Note that the financing of health care has no direct impact on the balanced growth system. Given that labor supply is inelastic with respect to the net wage the tax itself constitutes a neutral redistribution of resources from households to the government. Similarly, given perfect competition within the health care sector, private payments balance out with the wage bill.

For the analysis to be non-trivial we assume in the following the existence of two values $\underline{h}$ and $\bar{h}$, satisfying $0 \leq \underline{h}<\bar{h}<h_{\max }$, such that

$$
h \in[\underline{h}, \bar{h}] \Leftrightarrow g>0 .
$$

As part of the Proof of Proposition 2 we will characterize this somewhat more precisely. ${ }^{16}$ At this stage, we note that the interval $[\underline{h}, \bar{h}]$ is non-empty if at least one $h$ satisfies

$$
[\ell(h)-h] N>\frac{1}{\alpha \lambda}\left[\rho+\frac{\mu(h)[\rho+\mu(h)]}{\xi}\right] .
$$

This condition ensures that at least for one level of health care, the workforce available for production and $\mathrm{R} \& \mathrm{D}$ exceeds the weighted sum of discount rate and generational turn-over. ${ }^{17}$ We can now establish the following Proposition.

Proposition 1. (i) The system (28)-(30) describes a unique and stable balanced growth path. (ii) Given positive growth as described by (31), the comparative static effects of an increase in health care per capita, $h$, are given by

$$
\begin{aligned}
& \frac{d r}{d h}<0 \quad \text { and } \quad \frac{d \xi}{d h}<0 \quad \text { if } \quad \ell^{\prime} \leq 1 \\
& \frac{d g}{d h}=\lambda\left(\ell^{\prime}-1\right) N-\frac{1}{\alpha} \frac{d r}{d h}>0 \quad \text { if } \quad \ell^{\prime} \geq 1 .
\end{aligned}
$$

Proof. See Appendix B.1.

Generally, greater provision of health lowers the interest rate and the consumptioncapital ratio if it does not generate a surplus of effective labor available for $R \& D$ and final goods production $\left(\ell^{\prime} \leq 1\right)$. By contrast, the growth rate of GDP increases in the level of health care if the additional provision does not generate a reduction in the effective labor available for $\mathrm{R} \& \mathrm{D}$ and final goods production $\left(\ell^{\prime} \geq 1\right)$.

Remark 1. For $h \notin[\underline{h}, \bar{h}]$ and, therefore, $g=0$, it is readily verified that $d r / d h<0$ and $d \xi / d h<0$ [See (62) in the proof]. With zero RED employment, $L_{A}=0$, an expansion of the health care sector is necessarily pulling labor from final goods production. The resulting increase in capital intensity implies both a reduction in the rental rate (and interest rate) and a reduction in the consumption-capital ratio.

\footnotetext{
${ }^{16}$ Note that by definition $h_{\max }=\ell\left(h_{\max }\right)$ it must be true that $\left.g\right|_{h=h_{\max }}<0$, implying immediately that $\bar{h}<h_{\max }$.

${ }^{17}$ In the conventional Romer (1990) framework, where $h=\mu(h)=0$ this condition boils down to $\ell N>\rho(\alpha \lambda)^{-1}$, i.e., the available labor force must exceed the weighted discount rate.
} 
In the following we continue to focus on the interval $h \in[\underline{h}, \bar{h}]$ for which positive growth $g>0$ obtains. To understand in greater detail the impact of health care on the growth path, it is instructive to consider in separate the impact through improvements in productivity/labor participation, i.e., through $\ell^{\prime}>0$, and through reductions in mortality, i.e., through $\mu^{\prime}<0$. Consider first the case in which health care has an impact on effective labor supply only, i.e., $\ell^{\prime}>0=\mu^{\prime}$, so that economic growth is affected only through changes in the labor available for production and $R \& D$. The following is readily verified from (57)-(59) in the Proof of Proposition $1 .^{18}$

Corollary 1. If $\ell^{\prime}>0=\mu^{\prime}$, i.e., if health care only has an impact on effective labor supply, we have $d r / d h \geq 0, d \xi / d h \geq 0$ and $d g / d h \geq 0$ if and only if $\ell^{\prime} \geq 1$.

If an expansion of health care increases effective labor but has no impact on mortality, then it boosts the interest rate, the consumption-capital ratio and the growth rate as long as it creates a surplus of effective labor available for $\mathrm{R} \& \mathrm{D}$ and production. The net expansion of available labor leads to an instantaneous increase in $\mathrm{R} \& \mathrm{D}$ employment and output of blueprints, $A$. The latter triggers an increase in the number of intermediate goods producers and, through the increase in competition, to an erosion of both the profits $\pi$ in the intermediate goods sector and of the price for blueprints, $p_{A}$. At the same time, the demand for additional capital that comes with the expanding production of intermediate goods triggers an increase in the interest rate. A greater variety of machines is now employed in final goods production, where the greater 'machine' intensity induces an increase in wages, $w_{Y}$. At the same time, the price erosion for blueprints triggers a reduction in $\mathrm{R} \& \mathrm{D}$ wages, $w_{A}$. The resulting wage differential $w_{Y}-w_{A}>0$ induces a flow of labor from the $R \& D$ sector into final goods production up to the point at which wages are equalized across sectors at a lower level, the latter reflecting the increase in the overall supply of effective labor. ${ }^{19}$ At the same time, employment has increased in both sectors, as we see from (19) together with (27), whereby $g=\lambda L_{A}$ and, therefore, $d L_{A} / d g=\lambda>0$; and from (25), whereby $d L_{Y} / d r>0$. Finally, although the increase in the interest rate induces individuals to save more, the output of final goods expands by so much that, nevertheless, aggregate consumption increases relative to the level of wealth. The simultaneous increase in aggregate consumption and savings indicates a clear improvement in economic conditions. All of these effects reverse if the provision of health care is expanded to a point at which its production requires more labor than is effectively generated. In this case, workers are drawn into the health care sector from both the $\mathrm{R} \& \mathrm{D}$ sector and final goods production. At the same time, the prices for blueprints increase, stifling the production of both intermediate and final goods. The former triggers a reduction in the interest rate, and the latter a reduction in the consumption-capital ratio.

Now consider the scenario where health care has an impact on mortality only, i.e.,

\footnotetext{
${ }^{18}$ Note that for $\mu^{\prime}=0$ we have $X 2_{h}=0$.

${ }^{19}$ This can be verified from (51) in Appendix A.4, where the normalized wage rate $w / Y$ falls in $r$.
} 
$\ell^{\prime}=0>\mu^{\prime}$. The following is easy to verify.

Corollary 2. If $\ell^{\prime}=0>\mu^{\prime}$, i.e., if health care only has an impact on mortality, we have $d r / d h<0, d \xi / d h<0$ for all $h \in[\underline{h}, \bar{h}]$ and $d g / d h>0$ if and only if $d r / d h<-\alpha \lambda N$.

If an expansion of health care lowers mortality but has no impact on the supply of effective labor, then it always lowers the interest rate and the consumption-capital ratio, while it increases the rate of economic growth if and only if the reduction in the interest rate is sufficiently pronounced. Within this scenario, an expansion of health care always reduces the effective labor available for $\mathrm{R} \& \mathrm{D}$ and production. Whether or not this stifles economic growth, however, depends crucially on the impact of health care on the interest rate. Here, we note that the reduction in mortality that is triggered by an expanding health care sector leads to a decline in the turnover effect and, thus, to an increase in aggregate savings. This, in turn, leads to a reduction in (a) the aggregate consumption-capital ratio, and (b) the interest rate, the latter implying a greater output by established producers of intermediate goods and, thus, a more 'machine' intensive production of final goods. At the same time, the reduction in the interest rate implies an increase in the price for blueprints and, in turn, an increase in the wage paid to R\&D workers. This induces a flow of workers from production into R\&D up to the point that wages are equalized at a higher level. Hence, the impact of an expanding health care sector on $R \& D$ employment is ambiguous: On the one hand, available labor is shifted to the health care sector, implying a tendency toward lower R\&D employment; on the other hand, labor is induced to shift from production into $\mathrm{R} \& \mathrm{D}$, implying a tendency toward greater $\mathrm{R} \& \mathrm{D}$ employment. Indeed, the overall effect on R\&D employment and, thus, on technological progress is positive if and only if $d r / d h<-\alpha \lambda N .^{20}$ This condition is the more likely to be satisfied, the stronger is the negative impact on the interest rate through the reduction in mortality (and generational turnover), the larger is the labor share in final goods production, $1-\alpha$, and the smaller is the 'growth potential', $\lambda N$. A large labor share in final goods production implies high employment $L_{Y}=(r-\delta) / \alpha \lambda$ and, therefore, also a strong leverage on employment of changes in the interest rate; a small 'growth potential' implies a weak direct impact on $\mathrm{R} \& \mathrm{D}$ production of an increase of employment within the health care sector.

Combining the effects through mortality and morbidity affords the general statement in Proposition 1. As a more rigorous characterization, we can now establish the following result.

Proposition 2. Given the assumptions in (10) and (12), there exists a unique level $\widehat{h}_{g} \in$ $\left(0, h_{\max }\right)$ at which the growth rate is maximized if the following set of conditions holds: (i) either $\left.\ell^{\prime}\right|_{h=0} \geq 1$ or $\left.\mu^{\prime}\right|_{h=0}$ sufficiently large in absolute value; and (ii) $\left.\mu^{\prime}\right|_{h=h_{\max }}$ sufficiently close to zero.

Proof. See Appendix B.2.

\footnotetext{
${ }^{20}$ To see this, set $\ell^{\prime}=0$ in $(32)$.
} 
Remark 2. A more precise condition for ' $\mu$ ' $\left.\right|_{h=0}$ sufficiently large in absolute value' and ' $\left.\mu^{\prime}\right|_{h=h_{\max }}$ sufficiently close to zero', respectively, is given in the proof.

Economic growth is maximized at a unique level of health care, $\widehat{h}_{g} \in\left(0, h_{\max }\right)$, if (i) the first introduction of health care (i.e., at $h=0$ ) guarantees a sufficient reduction in mortality and/or a sufficient increase in effective labor; and (ii) if at the maximum feasible level of health care (i.e., at $h=h_{\max }$ ), the impact on mortality is sufficiently low. Indeed both sets of conditions are plausible: As is easy to envisage, the returns to introducing a health care sector into an economy are prone to be substantive, while decreasing returns should be expected to result in 'flat of the curve' medicine (cf. Fuchs, 2004) without any sizable gains well before the full labor force is employed in health care.

Building on the findings in Corollaries 1 and 2 it is easy to establish the following.

Corollary 3. Let (i) $\left.\ell^{\prime}\right|_{h=0}>1$, $\ell^{\prime \prime}<0$; (ii) $\left|\mu^{\prime}\right|,\left|\mu^{\prime \prime}\right|$ sufficiently small; and (iii) $\underline{h}=0$. Then there exist $\widehat{h}_{\xi} \in(0, \bar{h})$ and $\widehat{h}_{r} \in(0, \bar{h})$ at which the consumption-capital ratio and the interest rate, respectively, are maximized. More specifically, we have $\widehat{h}_{\xi} \leq \widehat{h}_{r} \leq\left. h\right|_{\ell^{\prime}=1} \leq$ $\widehat{h}_{g}$ with strict inequalities (equalities) if $\mu^{\prime}<0\left(\mu^{\prime}=0\right)$.

Proof. See Appendix B.3.

Provided that the impact of health care on mortality is not too strong relative to its impact on effective labor supply, the interest rate and consumption capital ratio also exhibit a hump-shaped relationship with health care. As is illustrated in Figure 2, when increasing the level of health care from zero, the consumption-capital ratio peaks first, followed by the peak of the interest rate.

If health care has an impact on mortality, $\mu^{\prime}<0$, both $\xi$ and $r$ peak at levels of $h$ at which a further increase still leads to an expansion of the labor force available for R\&D and production (i.e., where $\ell^{\prime}>1$ ). This is owing to the negative impact of mortality reductions on generational turnover, where the associated increase in aggregate financial wealth pushes toward a lower aggregate consumption-savings ratio and a lower interest rate (see Corollary 2). At the same time the shift of workers from final goods production into $\mathrm{R} \& \mathrm{D}$ that is afforded by the reduction in the interest rate allows to sustain a positive impact of $h$ on economic growth even beyond the level $\left.h\right|_{\ell^{\prime}=1}$, at which the available labor force is maximized. Only in the absence of mortality-related effects of health care $\left(\mu^{\prime}=0\right)$ do all three variables $\xi, r$ and $g$ peak at the same level $\left.h\right|_{\ell^{\prime}=1}$.

According to Figure 2 the impact of health care on the distribution of the workforce across the different sectors can be grouped into three distinct regimes: For low levels of health care, $h \in\left[0, \widehat{h}_{r}\right]$, the boost in the effective labor supply afforded by an increase in the health care sector allows an expansion of employment within all sectors: health care, final goods production and $\mathrm{R} \& \mathrm{D}$. Note that up to this point final-goods output per unit of capital $Y / K=r / \alpha^{2}$ (see Appendix A.4) also grows. For intermediate levels $h \in\left[\widehat{h}_{r}, \widehat{h}_{g}\right]$ the reduction in the interest rate triggered by a further expansion of public 


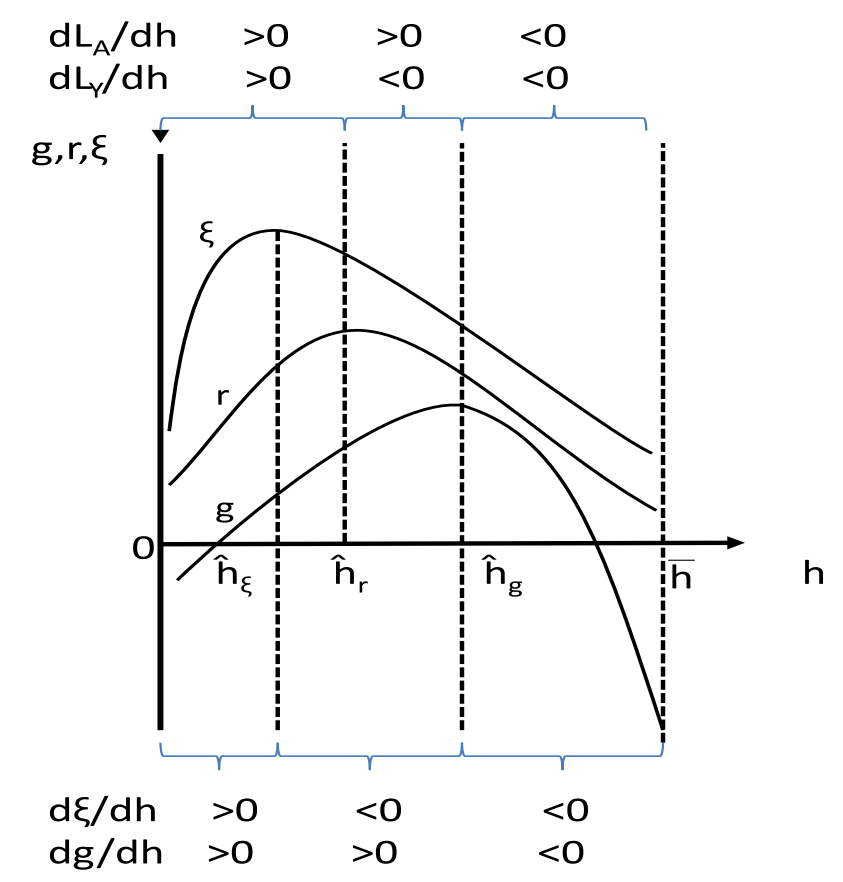

Figure 2: Dependency of $g, r$ and $\xi$ on health care, when $\left.\ell^{\prime}\right|_{h=0}>1, \ell^{\prime \prime}<0$ and $\left|\mu^{\prime}\right|,\left|\mu^{\prime \prime}\right|$ small.

health now leads to shift of employment from final goods production to $R \& D$, the latter of which continues to grow. Interestingly, final goods employment decreases on the interval $\left[\widehat{h}_{r},\left.h\right|_{\ell^{\prime}=1}\right]$ although the effective labor available for $\mathrm{R} \& \mathrm{D}$ and production continues to grow. On this interval the R\&D sector benefits both from 'new' effective units of labor and from labor being transferred from production. Note that this effect follows from the generation of additional capital due to reduced turnover. Similarly, the R\&D sector continues to grow even if for $h \in\left[\left.h\right|_{\ell^{\prime}=1}, \widehat{h}_{g}\right]$ the health care sector is now employing more effective labor than it is generating. Finally, for high levels $h \in\left[\widehat{h}_{g}, h_{\max }\right]$ employment is drawn into the health care sector from both final goods production and R\&D despite the ongoing increase of the aggregate labor force $L=\ell(h) N$.

\section{Numerical Assessment for the Euro Area}

In this subsection we calibrate the model, fitting it to the life expectancy $e_{0}=\mu(h)^{-1}$, labor force participation $l(h)$ and the growth experience over the last decade for the Euro area. In so doing we address the questions as to what is approximately the growth-maximizing size of the health care sector and how it compares to the actual size.

In our calibration we use the functions $\mu(h)=0.00275 h^{-1 / 2}$ and $l(h)=0.405+0.6 h$ because they satisfy the properties in (10) and (12) and imply life expectancy at birth $e_{0}$ and labor force participation $l \in[0,1]$ consistent with the observed values. Furthermore, we use the parameters displayed in Table 1, where 10-year average values over the years 2000 to 2009 were obtained for the population size and the health share (i.e., health 
expenditures as a ratio of GDP). This has been done to get rid of short-run changes in the health share that could be due to business-cycle fluctuations. Note that an observed health share $(G / Y)$ of $9.78 \%$ implies that $4.79 \%$ of the population are employed in the health sector. ${ }^{21}$

Table 1: Parameter values for calibration

\begin{tabular}{lrr}
\hline \hline Parameter & Value & Justification \\
\hline \hline$\rho$ & 0.015 & Auerbach and Kotlikoff (1987) \\
$\alpha$ & 0.33 & Jones (1995) \\
$\delta$ & 0.05 & Full depreciation after 20 years \\
$\lambda$ & $6.41 \times 10^{-10}$ & To fit growth experience in EA \\
$N$ & 323040881 & World Bank (2012) \\
$G / Y$ & 0.0978 & World Bank (2012) \\
$h$ & 0.0479 & implied by equation (52) \\
& & in Appendix A.4 \\
\hline \hline
\end{tabular}

In order to assess the size of the health care sector at which economic growth is maximized we plot in Figure 3 the growth rate and its derivative with respect to $h$. We see that there is indeed an interior growth maximizing size of the health care sector at $h=0.0250$, i.e. at $2.5 \%$ of the total population working in health care. In expenditure terms, this corresponds to a health share of $4.73 \%$ of GDP, which is roughly in line with the data examined in Figure 1.

The actual values for $g, r-\delta, e_{0}, l$, and $G / Y$ are displayed in Table 2 together with the calibrated values and the values at the point at which economic growth is maximized. To get rid of business-cycle influences, the actual values are again 10-year averages over the years 2000 to 2009 obtained from data of the World Bank (2012). In case of interest rates the 7-year average of long-term interest rates net of inflation over the years 2000 to 2006 were obtained using data from EUROSTAT. First, we note that our calibrated data matches the actual data with considerable accuracy. Second, our results suggest that developed economies like the Euro area have health sectors that are too large from the perspective of maximizing economic growth. Third, however, we note that while the current size of the health care sector does not even "cost" 0.02 percentage points in terms of growth rates foregone, the gain in life expectancy of almost 22 years is sizable by all accounts. Given that economic growth considerations can only be one aspect of health policy, our numerical results suggest that concerns about the welfare costs of excessively large health care sectors may be exaggerated. In the following section we provide a theoretical argument that a limited expansion of health care beyond the growth-maximizing level may well constitute a Pareto-improvement.

\footnotetext{
${ }^{21}$ Recall that $h=L_{H} / N$ measures health care employment relative to full population size.
} 

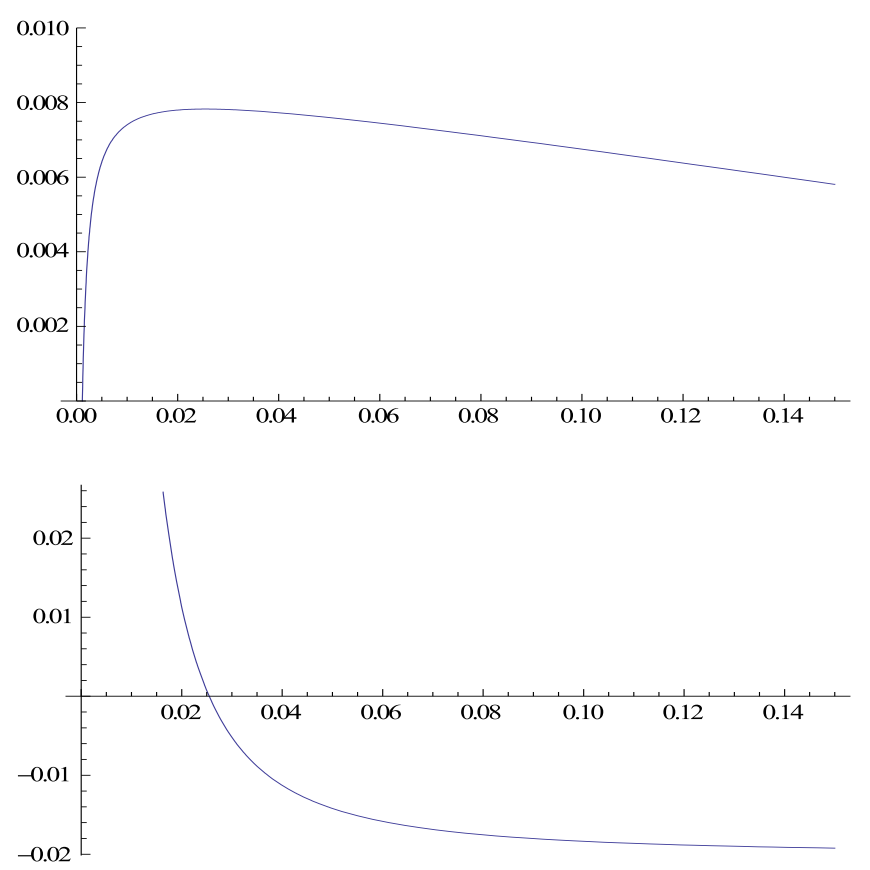

Figure 3: The economic growth rate (panel (a)) and its derivative with respect to $h$ (panel (b)) for $h \in[0,0.15]$.

\section{The Welfare Impact of Health Care}

We conclude our analysis by considering the impact of an expanding health care sector on the life-cycle utility of different cohorts. Following Saint-Paul (1992) we can express the indirect life-cycle utility of a member of cohort $t_{0}$ at time $t \geq t_{0}$ as

$$
U\left(t_{0}, t\right)=\frac{\log c\left(t_{0}, t\right)}{\rho+\mu}+\frac{r-\rho-\delta}{(\rho+\mu)^{2}},
$$

where the first term reflects the discounted value of the utility stream from consumption at current level $c\left(t_{0}, t\right)$ and where the second term reflects the discounted benefit from changes in consumption over the remaining life-course. In Appendix A.3, equation (45)

Table 2: Simulation Results

\begin{tabular}{lrrr}
\hline \hline & Actual & Calibrated & Growth Maximizing \\
\hline$g$ in $\%$ & 0.81 & 0.81 & 0.83 \\
$r-\delta$ in $\%$ & 2.24 & 2.37 & 2.23 \\
$e_{0}$ in years & 79.45 & 79.56 & 57.54 \\
$l$ in $\%$ & 43.64 & 43.37 & 42.00 \\
$G / Y$ in $\%$ & 9.78 & 9.78 & 4.72 \\
\hline \hline
\end{tabular}


we derive the consumption level

$$
c\left(t_{0}, t\right)=(\rho+\mu)\left[k\left(t_{0}, t\right)+\omega(t)\right],
$$

with $k\left(t_{0}, t\right)$ denoting the financial wealth of a member of cohort $t_{0}$ at time $t$, and

$$
\begin{aligned}
\omega(t) & =\int_{t}^{\infty}\left[(1-\tau) w(s) \ell+d(s)-p_{H}(s) \sigma h\right] e^{-(r+\mu-\delta)(s-t)} d s \\
& =\frac{\left(1-\alpha^{2}\right) Y(t)}{N(r+\mu-\delta-g)}>0,
\end{aligned}
$$

denoting human wealth at time $t$ (see Appendix A.6 for a derivation). Thus, at each point in time consumption increases with the sum of financial wealth and human wealth, and with the marginal propensity to consume, $\rho+\mu$. Human wealth amounts to the discounted stream of (expected) net income over the remaining life-course, which on a balanced growth path can be expressed as a function of the GDP per capita at time $t$ and the 'net' discount rate $r+\mu-\delta-g>0$, where the inequality is readily verified from (29).

Similar to Saint-Paul (1992) we examine the effects on the life-cycle utility of the various cohorts of an unanticipated policy change. Specifically, we consider how an unanticipated and marginal "health care reform" $d h(t)$ at time $t=0$ affects the life-cycle utility of (i) a member of the current generation born at $t_{0}=0$; (ii) a member of a future cohort born at $t_{0}>0$; and (iii) a member of a 'past' cohort born at $t_{0}<0$. From (33) we obtain for $t \geq 0$

$$
\begin{aligned}
\frac{d U\left(t_{0}, t\right)}{d h(0)}= & \frac{-\mu^{\prime}}{(\rho+\mu)^{2}}\left[\log c\left(t_{0}, t\right)+\frac{2(r-\rho-\delta)}{\rho+\mu}\right] \\
& +\frac{1}{(\rho+\mu) c\left(t_{0}, t\right)} \frac{d c\left(t_{0}, t\right)}{d h(0)}+\frac{1}{(\rho+\mu)^{2}} \frac{d r}{d h(0)}
\end{aligned}
$$

Here, the RHS term in the first line reflects the change in life-cycle utility due to the reduction in mortality. Assuming that representative life-cycle utility is non-negative, i.e., assuming that $U\left(t_{0}, t\right) \geq 0$, it follows that an expansion of life-expectancy unambiguously raises life-cycle utility. The first term in the second line reflects the impact through changes in the consumption level $c\left(t_{0}, t\right)$. The second term in the second line reflects the impact of health-induced changes in the interest rate on consumption growth over the life-cycle. This effect is negative if increases in the health care sector lead to a depression in the interest rate and, thus, to reduced individual saving.

Noting that lack of anticipation implies that a health care reform at $t=0$ has no impact on the financial wealth $k\left(t_{0}, t\right)$ of an individual belonging to a cohort $t_{0}<0$, we obtain

$$
\frac{d c\left(t_{0}, t\right)}{d h(0)}=\mu^{\prime}\left[k\left(t_{0}, t\right)+\omega(t)\right]+(\rho+\mu) \frac{d \omega(t)}{d h(0)},
$$


where $^{22}$

$$
\begin{aligned}
\frac{d \omega(t)}{d h(0)} & =\frac{\omega(t)}{r+\mu-\delta-g}\left[\frac{1}{Y(t)} \frac{d Y(t)}{d h(0)}-\frac{d r}{d h(0)}-\mu^{\prime}+\frac{d g}{d h(0)}\right] \\
& =\frac{\omega(t)}{r+\mu-\delta-g}\left[(t+1) \frac{d g}{d h(0)}-\frac{d r}{d h(0)}-\mu^{\prime}\right] .
\end{aligned}
$$

Consumption $c\left(t_{0}, t\right)$ tends to decrease in the level of health care to the extent that lower mortality reduces the individual's propensity to consume, reflecting the need to stretch consumption over an extended life-course. This effect is moderated by the impact of health care on human wealth, the latter being ambiguous in its own right: By reducing the effective discount rate a mortality reduction contributes toward boosting the present value of human wealth at time $t \geq 0$. However, further and possibly offsetting effects arise through changes in the level and growth of GDP and through changes in the interest rate.

The various offsetting and indeterminate effects in (36) make it difficult to establish a utility-maximizing level of health care. We therefore restrain ourselves to examining the variation in the life-cycle utility of different cohorts for local changes in the level of health care around the growth maximizing level $\widehat{h}_{g}$. Considering the sign of the derivative $d U\left(t_{0}, t\right) /\left.d h(0)\right|_{h(0)=\widehat{h}_{g}}$ allows us to establish whether or not a cohort described by (i) $(0,0)$ : current, (ii) $\left(t_{0}, t_{0}\right)$ with $t_{0}>0$ : future, and (iii) $\left(t_{0}, 0\right)$ with $t_{0}<0$ : past, benefits from a (small) expansion in the provision of health care beyond the growth-maximizing level. Note here that distinctions arise with respect to the impact of health reform on the consumption level $c\left(t_{0}, t\right)$. Specifically, we note that $k\left(t_{0}, t_{0}\right)=0$ applies in (37) for cases (i) and (ii), as newborn cohorts do not possess initially financial wealth; and that $t=0$ and, therefore, $d Y(0) / d h(0)=0$ applies in (38) for cases (i) and (iii), as the impact on life-cycle wealth of a reform at $t=0$ is instantaneous for current and past cohorts.

We begin by considering the special case where for $\mu^{\prime}=0$ health care bears on productivity only.

Proposition 3. For $\mu^{\prime}=0$ we obtain $d U\left(t_{0}, t\right) /\left.d h(0)\right|_{h=\widehat{h}_{g}}=0$ for all $t_{0}$ and $t \geq 0$, which corresponds to a maximum utility for all cohorts current, future and past.

Proof. See Appendix B.4.

If health care only bears on productivity/labor participation, then it is Pareto-efficient to provide it at the level that maximizes economic growth. Setting $\mu^{\prime}=0$ in (36)-(38) we obtain

$$
\begin{aligned}
\frac{d U\left(t_{0}, t\right)}{d h(0)} & =\frac{1}{(\rho+\mu) c\left(t_{0}, t\right)} \frac{d c\left(t_{0}, t\right)}{d h(0)}+\frac{1}{(\rho+\mu)^{2}} \frac{d r}{d h(0)} \\
& =\frac{1}{c\left(t_{0}, t\right)} \frac{d \omega(t)}{d h(0)}+\frac{1}{(\rho+\mu)^{2}} \frac{d r}{d h(0)} \\
& =\frac{\omega(t)}{c\left(t_{0}, t\right)(r+\mu-\delta-g)}\left[(t+1) \frac{d g}{d h(0)}-\frac{d r}{d h(0)}\right]+\frac{1}{(\rho+\mu)^{2}} \frac{d r}{d h(0)}
\end{aligned}
$$

\footnotetext{
${ }^{22}$ Note that for $Y(t)=Y(0) e^{g t}$, we obtain $d Y(t) / d h_{0}=t Y(t) d g / d h_{0}$.
} 
implying that the impact on life-cycle utility at $\left(t_{0}, t\right)$ is only shaped by changes in current consumption as opposed to changes in future consumption. Furthermore, changes in current consumption are exclusively driven by changes in human wealth. Recall from Corollaries 1 and 3 that for $\mu^{\prime}=0$ the growth-maximizing level of health care coincides with the level of care that maximizes the interest rate (and at the same time the workforce available for R\&D and production). But then it is immediate that $d U\left(t_{0}, t\right) /\left.d h(0)\right|_{h(0)=\widehat{h}_{g}}=$ $d g /\left.d h(0)\right|_{h(0)=\widehat{h}_{g}}=d r /\left.d h(0)\right|_{h(0)=\widehat{h}_{g}}=0$. For $h(0)<\widehat{h}_{g}$ a further health-driven increase in the growth rate contributes toward greater human wealth, and, thus, toward a greater level of current consumption. While the concomitant increase in the interest rate tends to depress the level of current consumption, it can be verified (see the proof of Proposition 3 in Appendix B.4) that this effect is over-compensated in terms of life-cycle utility by the increase in future consumption. These effects reverse, when additional health care leads to a depression in economic growth and the interest rate for $h(0)>\widehat{h}_{g}$.

Turning now to the general case where for $\mu^{\prime}<0$ health care also reduces mortality, we can establish the following intermediate result for cohorts $t_{0} \leq 0$ who are alive at the introduction of the reform $d h(0)>0$.

Lemma 1. If $\mu \leq \alpha \xi$ then there exists a $\widehat{t}_{0} \in(-\infty, 0]$ such that (i) $d c\left(t_{0}, 0\right) /\left.d h(0)\right|_{h(0)=\widehat{h}_{g}} \leq 0$ if and only if $t_{0} \leq \widehat{t}_{0}$ (with strict equality only for $t_{0}=\widehat{t}_{0}$ ); and (ii) $d U\left(\widehat{t}_{0}, 0\right) /\left.d h(0)\right|_{h(0)=\widehat{h}_{g}} \leq d U\left(t_{0}, 0\right) /\left.d h(0)\right|_{h(0)=\widehat{h}_{g}}$ for all $t_{0} \leq 0$ with a strict inequality for all $t_{0} \neq \widehat{t}_{0}$.

Proof. See Appendix B.5.

Provided mortality is not too large ${ }^{23}$, there exists a cohort $\widehat{t}_{0}$ for whom the level of consumption $c\left(t_{0}, 0\right)$ is unaffected by a small increase in health care beyond the growthmaximizing level, while it decreases for older cohorts $\left(t_{0}<\widehat{t}_{0}\right)$ and increases for younger cohorts $\left(t_{0}>\widehat{t}_{0}\right)$. At the same time, cohort $\widehat{t}_{0}$ is the one to receive the lowest marginal benefit from an increase in health care. To understand these results, we note that the impact of an unanticipated increase in health care at $t=0$ on the consumption level $c\left(t_{0}, 0\right)$ and the life-cycle utility $U\left(t_{0}, 0\right)$ of cohorts born prior to the reform $\left(t_{0}<0\right)$ is modified by the presence of financial wealth $k\left(t_{0}, 0\right)>0$. It is readily established that $d k\left(t_{0}, 0\right) / d t_{0}<0$, implying that later born cohorts have accumulated less wealth.

Setting $d g /\left.d h(0)\right|_{h(0)=\widehat{h}_{g}}=0$ in equation (38) it follows immediately that $d \omega /\left.d h(0)\right|_{h(0)=\widehat{h}_{g}}>0$. Hence, an increase in health care from its growth maximizing level tends to raise human wealth and, thereby, has a positive effect on the consumption level $c\left(t_{0}, 0\right)$ that is offsetting the decline in the marginal propensity to consume. However, as we also note from equation (37), the negative impact on consumption increases with the level of financial wealth $k\left(t_{0}, 0\right)$, implying that for a given change in human capital,

\footnotetext{
${ }^{23}$ Note that the condition $\mu<\alpha \xi$ will typically hold. For our numerical analysis we have assumed $\alpha=1 / 3$ and obtain $\left.\mu\right|_{h(0)=\widehat{h}_{g}}=0.0179$ and $\left.\xi\right|_{h(0)=\widehat{h}_{g}}=0.6185$ (see Tables 1 and 2 ) implying that the above inequality holds by an order of magnitude.
} 
financially wealthier cohorts have a greater tendency to reduce their consumption level. As it then turns out, the level of consumption $c\left(t_{0}, 0\right)$ declines at the point of the reform for older and wealthier cohorts $\left(t_{0}<\widehat{t}_{0}\right)$. Since consumption growth also declines for $d r /\left.d h(0)\right|_{h(0)=\widehat{h}_{g}}<0$, it follows that all cohorts $t_{0} \leq \widehat{t}_{0}$ suffer an unambiguous reduction in life-cycle consumption. For these cohorts, there is a clear trade-off between greater survival (quantity of life) against consumption (quality of life) (see e.g. Murphy and Topel, 2006; Hall and Jones, 2007). In contrast, younger and poorer cohorts $\left(t_{0}>\widehat{t}_{0}\right)$ are able to raise their consumption level $c\left(t_{0}, 0\right)$ at the point of reform. As these cohorts, too, are affected by lower growth in individual consumption, the impact on their life-cycle consumption is ambiguous.

Let us now compare members of cohort $\widehat{t}_{0}$ against their older and younger 'peers'. Although suffering from greater reductions in life-cycle consumption, older cohorts $\left(t_{0}<\widehat{t}_{0}\right)$ start with greater levels of consumption to begin with, $c\left(t_{0}, 0\right)>c\left(\widehat{t}_{0}, 0\right)$, and therefore experience greater direct gains from an expansion in life-expectancy. Due to their (relatively) greater benefit from the boost in human wealth, younger cohorts $\left(\widehat{t}_{0}<t_{0}\right)$ do not suffer as much as cohort $\widehat{t}_{0}$ from reductions in life-cycle consumption. It then turns out that members of the 'middle-aged' cohort $\widehat{t}_{0}$ are, indeed, least prone to benefit from an increase in health care: They are too poor to benefit sufficiently from an extension of their life-time, while at the same time they are too rich to benefit sufficiently from the increase in human wealth.

We can now establish the main result of the welfare analysis.

Proposition 4. For $\mu^{\prime}<0$ we obtain (i) $d U\left(t_{0}, t_{0}\right) /\left.d h(0)\right|_{h(0)=\widehat{h}_{g}}>0$ for all $t_{0} \geq 0$ if $\log c\left(t_{0}, t_{0}\right) \geq 0$; and (ii) $d U\left(t_{0}, 0\right) /\left.d h(0)\right|_{h(0)=\widehat{h}_{g}}>0$ for all $t_{0}<0$ if $\log c(0,0) \geq 0$ and $\left.g\right|_{h(0)=\widehat{h}_{g}}$ sufficiently large.

Proof. See Appendix B.6.

If health care contributes toward lowering mortality, the current and future cohorts $\left(t_{0} \geq 0\right)$ stand to gain from an expansion of the health care sector beyond its growth maximizing level if they experience non-negative period utility from consumption (i.e., if $\left.\log c\left(t_{0}, t_{0}\right) \geq 0\right)$. For $h(0) \leq \widehat{h}_{g}$, improvements in survival contribute toward lifecycle utility over and above the growth-driven increase in human wealth. Intuitively, at $h(0)=\widehat{h}_{g}$ it seems efficient to incur a second-order loss in human wealth due to less than maximal growth in exchange for a first-order gain in life-expectancy [cf. RHS of the first-line in (36)]. Nevertheless, the finding that an increase in health care beyond the growth-maximizing level is always beneficial for current and future cohorts is by no means a foregone conclusion: This is because of the first-order loss from a reduction in consumption growth and potentially from a reduction in life-cycle consumption. ${ }^{24}$ As our

\footnotetext{
${ }^{24}$ Indeed, for $\mu \rightarrow \alpha \xi$ we have $d c\left(t_{0}, t_{0}\right) / d h(0)=0$ for all $t_{0} \geq 0$ so that these cohorts, too, would suffer a reduction in life-cycle consumption.
} 
analysis reveals, however, at the point at which growth is maximized, $h(0)=\widehat{h}_{g}$, the tradeoff goes unambiguously in favor of survival, so that current and future cohorts benefit from an increase in health care beyond the growth-maximizing level. Cohorts differ, however, in their propensity to benefit. In the presence of economic growth, future cohorts born at $t_{0}>0$ tend to benefit from greater human wealth at the point of their birth, $\omega\left(t_{0}\right)>\omega(0)$, allowing them to sustain a greater level of baseline-consumption $c\left(t_{0}, t_{0}\right)>c(0,0)$. While this increases their marginal benefits from an extended life-time, at the same time they suffer from a greater negative impact on their human wealth of reductions in the growth rate below the maximum, where $\left(t_{0}+1\right) d g / d h(0)<d g / d h(0)<0$ in (38). Hence, while the current and future generations all stand to benefit from some increase in health care beyond the growth-maximizing level, they are prone to disagree about the extent.

When considering the impact of an unanticipated increase in health care at $t=0$ on the life-cycle utility of cohorts $\left(t_{0}<0\right)$ born prior to the reform, it is sufficient to focus on cohort $\widehat{t}_{0} \in(-\infty, 0]$ [Lemma 1 part (ii)]. Indeed, when considering a Pareto-improvement one would need to verify that the middle-aged cohort $\widehat{t}_{0}$ who is least prone to benefit from the reform does not experience a loss in life-cycle utility. We show in Appendix B.6 that cohort $\widehat{t}_{0}$ experiences a marginal change in life-cycle utility of

$$
\left.\frac{d U\left(\widehat{t_{0}}, 0\right)}{d h(0)}\right|_{h(0)=\widehat{h}_{g}}=\frac{-\mu^{\prime} \log c\left(\widehat{t}_{0}, 0\right)}{(\rho+\mu)^{2}}-\frac{2 \mu^{\prime}(r-\rho-\delta)}{(\rho+\mu)^{3}}+\left.\frac{1}{(\rho+\mu)^{2}} \frac{d r}{d h(0)}\right|_{h(0)=\widehat{h}_{g}},
$$

where the benefits from an expanding life-time (the first two terms on the RHS) trade-off against the reduction in individual consumption growth and, thus, in future consumption (the third term). This trade-off illustrates the ambiguous role of responses in the interest rate to expansions in longevity. On the one hand, we have seen that falling interest rates help to sustain economic growth by boosting R\&D incentives. On the other hand, by curbing individuals' saving incentives a falling interest rate leads to less consumption growth and, for a given level of current consumption, to a reduction in life-cycle consumption. At individual level, this undermines the very return to increases in life-expectancy. ${ }^{25}$ These arguments notwithstanding, even cohort $\widehat{t}_{0}$ benefits from an increase in health care if the (maximized growth) rate $\left.g\right|_{h(0)=\widehat{h}_{g}}$ is sufficiently large. Intuitively, a high growth rate implies a high interest rate, and, therefore, high rates of individual consumption growth, $\left.r\right|_{h(0)=\widehat{h}_{g}}-\rho-\delta>0$, to begin with. In this case, the direct benefits from lower mortality overcompensate the reduction in life-time consumption.

Corollary 4. If the conditions in Proposition 4 are satisfied, then an increase in the provision of health care beyond its growth-maximizing level is Pareto-optimal.

This corollary follows immediately, as all generations - past, current, and future - benefit from an expansion of the health care system beyond its growth-maximizing level. The

\footnotetext{
${ }^{25}$ Incidentally, the above trade-off provides another rationale for why models with endogenous interest rates should be considered. In a Romer (1986) type economy with a constant interest rate a small increase in health care from the growth-maximizing level would unambiguously benefit all cohorts.
} 
degree to which health care can be expanded without harming any generation is more difficult to determine, as cohorts not only differ in their propensity to benefit $d U\left(t_{0}, t\right) / d h(0)$ at $h(0)=\widehat{h}_{g}$ but also in the rate at which marginal utility declines (toward a negative level eventually) as growth rates deteriorate for $h(0)>\widehat{h}_{g}$. This notwithstanding, the result stated in the Corollary is strong in as far as it obtains under the assumption that past generations $t_{0}<0$ are unable to anticipate the health care reform at $t=0$. These generations are subject, therefore, to a jump in their consumption at $t=0$, militating against the desire to smooth consumption. Indeed, in anticipation of the reform these cohorts would likely choose a different pattern of capital accumulation on the interval $\left[t_{0}, 0\right]$, affording them a greater propensity to benefit from the increase in $h(0)$. Allowing for anticipation would therefore only strengthen our result. We conclude by pointing out that the result in the Corollary is also rather plausible. Using the parameters and variables from our numerical example in the previous section (see Tables 1 and 2) to calculate the critical value for the growth rate as given by (73) in Appendix B.6 we obtain that generation $\widehat{t}_{0}$ benefits from a marginal increase in $h(0)$ if $\left.g\right|_{h(0)=\widehat{h}_{g}}>3.27 \times 10^{-4}$. This condition is clearly satisfied, as we obtain a maximal growth rate of $\left.g\right|_{h(0)=\widehat{h}_{g}}=8.3 \times 10^{-3}$ (as stated in Table 2).

\section{Conclusions}

We have developed an R\&D-based economic growth model featuring a Blanchard-Yaari OLG structure with a health-dependent mortality rate. Our model provides an explanation for the hump-shaped relationship between economic growth and health care based on the allocation of labor across three sectors: health care, final goods production (i.e., manufacturing) and R\&D. If, by raising productivity and/or labor participation, health care contributes toward expanding the effective workforce that is available for $\mathrm{R} \& \mathrm{D}$, then uncontroversially its expansion has a positive impact on economic growth. However, our analysis shows that even if an expansion of health care diverts labor away from productive sectors, which empirically is true for many countries, it may nevertheless enhance growth by inducing a flow of workers from manufacturing into $\mathrm{R} \& \mathrm{D}$. The rationale for such a redirection of labor is that the level of accumulated wealth increases with a health-induced increase in longevity, triggering a drop in the interest rate and an increase in capital (machine) intensity in manufacturing. Both of these effects imply that the intermediate production of machines and, in turn, the design of blueprints becomes more profitable. The relative increase in wage rates paid within the $R \& D$ sector then attracts labor away from manufacturing. Hence, by pushing toward a greater capital intensity of manufacturing, an expansion of health care may stimulate or at least sustain R\&D-driven growth. This notwithstanding, we show that if the health sector becomes too large it will divert labor away not only from manufacturing but also from $R \& D$ and, therefore, ultimately stifle growth.

While a numerical example suggests that the provision of health care within the Euro 
area is excessive from a growth-maximizing point of view, this need not necessarily be detrimental to economic welfare. We show that an expansion of health care beyond its growth-maximizing level may be Pareto-optimal even if it leads to a first-order reduction in consumption for some cohorts. A sufficient condition for Pareto-optimality is that the economic growth rate and, implicitly, the growth rate of individual consumption is sufficiently high to begin with. Finally, our analysis gives some guidance as to what are the trade-offs faced by particular cohorts: On the one hand, older and wealthier cohorts tend to secure a greater direct benefit from an expansion in longevity, owing to the greater level of consumption and period utility they obtain; on the other hand, they benefit to a lesser extent from a health-driven increase in human wealth and, therefore, they are more prone to experience larger cuts to their life-cycle consumption. Therefore, the trade-off between quantity of life (longevity) and quality of life (consumption) is increasing with age. This notwithstanding, it is the middle-aged cohorts who are the least prone to benefit from an expansion of health care: Having accumulated intermediate levels of financial wealth, these cohorts are too poor to benefit extensively from an increase in longevity, while at the same time they are too rich to benefit from an increase in human wealth.

From a policy-perspective our model implies that concerns about negative growth effects of an expanding health care sector may be exaggerated. This is first because an expanding health-care sector may be an engine of technological progress even if it diverts otherwise productive labor resources. Second, there are good grounds to believe that even if health care has expanded to levels at which it is harmful to economic growth, this may still be socially valuable as part of an optimal trade-off between quantity of life (longevity) and quality of life (consumption). For a policy-maker with distributional concerns and/or with concerns about enlisting political support, it is important to understand how the benefits of additional health care are distributed across generations. Our analysis suggests that a policy-maker who is interested in unanimous support and/or worried about those with the greatest potential to lose out from an increase in health care, should focus on cohorts of intermediate age and with intermediate levels of financial wealth.

We acknowledge that our model is highly stylized on a number of important dimensions: First, it assumes away the distortions in the provision and finance of health care that feature so prominently in most analyses on the topic. In particular, we assume that (i) there are no distortions from taxation, that (ii) health care providers do not garner any rents from monopoly power or from regulatory imperfections, and (iii) we ignore inefficiencies in the individual consumption of health care. Distortionary effects from taxation should be relatively straightforward to incorporate and understand: Here labor participation would not only vary positively with health care but also negatively with the tax rate, implying a net impact of health care that would likely to be positive at low levels of care and taxation but then shift to negative from some point. This would imply that from some point onwards an expansion of the health care sector would not only divert labor away from productive uses but also, potentially, reduce the aggregate supply of labor. While this would clearly indicate that growth is maximized at a lower level of care, we do 
not feel that any of our substantive results would change. Similarly, we would not expect that the presence of market power in the health care sector would change much unless we were to consider the explicit choice of health care by individuals. In this case market power would imply too low a demand for health care, whereas health insurance and/or longevity-related moral hazard would imply the opposite. Finally, individuals would fail to internalize the impact of health care on economic growth. While longevity-related moral hazard and the failure to internalize growth effects are analyzed by Schneider and Winkler (2010), there is clear scope for additional study of imperfections within a Romer (1990) set-up.

Second, our modeling of the health care sector is rudimentary. While we believe that our focus on labor as the main input is broadly in line with empirical reality (cf. Pauly and Saxena, 2012), clearly we are abstracting from other inputs, and in particular from medical technology. Here, an integration of the health production function in van Zon and Muysken (2001), where health is produced from human capital (= labor) and a range of available technologies, could serve as a useful starting point to understand R\&D incentives and technological progress along two margins: conventional production and health care. Furthermore, we have treated health care as a composite output that contributes toward lowering mortality and morbidity alike. In reality, of course, health care is a highly differentiated good with many services affecting either mortality or morbidity but not both. Similarly, publicly and privately provided care may constitute imperfect substitutes or even complements (see e.g. Bhattacharya and Qiao, 2007).

Third, our results are very much based on a comparative static variation in the level of health care. Similar to most of the analysis based on Romer (1990) this is missing out on the transitory dynamics. In particular when considering the impact of health care reform such an analysis would be valuable. Finally, the focus of our analysis on the impact of health care on economic growth ignores the reverse causality from income to health. The latter is considered by Hall and Jones (2007) but, of course, it would be fruitful to examine both directions within one and the same framework. We reserve these considerations for future research. 


\section{References}

Acemoglu, D. and Johnson, S. (2007). Disease and Development: The Effect of Life Expectancy on Economic Growth. Journal of Political Economy, Vol. 115(No. 6):925985.

Aghion, P. and Howitt, P. (1992). A model of growth through creative destruction. Econometrica, Vol. 60(No. 2):323-351.

Aísa, R. and Pueyo, F. (2004). Endogenous longevity, health and economic growth: a slow growth for a longer life? Economics Bulletin, Vol. 9(No. 3):1-10.

Aísa, R. and Pueyo, F. (2006). Government health spending and growth in a model of endogenous longevity. Economics Letters, Vol. 90:249-253.

Altarum Institute (2012). Health Sector Economic Indicators. Labor Brief 12-06.

Attanasio, O., Kitao, S. and Violante G. L. (2007). Global demographic trends and social security reform. Journal of Monetary Economics, Vol. 54:144-198.

Auerbach, A. J. and Kotlikoff, L. J. (1987). Dynamic Fiscal Policy. Cambridge University Press.

Azomahou, T. T., Boucekkine, R. and Diene, B. (2009). A closer look at the relationship between life expectancy and economic growth. International Journal of Economic Theory, Vol. 5(No. 2): 201-244.

Barro, R. J. (1997). Determinants of Economic Growth: A Cross-Country Empirical Study. MIT Press, Cambridge MA.

Berger, M. C. and Messer, J. (2002). Public financing of health expenditures, insurance, and health outcomes. Applied Economics, Vol. 34: 2105-2113.

Bhargava, A., Jamison, D., Lawrence, L. and Murray, C. (2001). Modelling the effects of health on economic growth. Journal of Health Economics, Vol. 20:423-440.

Bhattacharya, J. and Qiao X. (2007). Public and private expenditures on health in a growth model. Journal of Economic Dynamics and Control, Vol. 31:2519-2535.

Blanchard, O. J. (1985). Debt, deficits and finite horizons. Journal of Political Economy, Vol. 93(No. 2):223-247.

Bloom, D. E. and Canning, D. (2000). The health and wealth of nations. Science, Vol. 287:1207-1209.

Bloom, D. E. and Canning, D. (2005). Health and Economic Growth: Reconciling the Micro and Macro Evidence. Center on Democracy, Development and the Rule of Law Working Papers. 
Bloom, D. E., Canning, D. and Sevilla, J. (2003). The Demographic Dividend: A New Perspective on the Economic Consequences of Population Change. Population Matters Monograph MR-1274, RAND, Santa Monica.

Bureau of Labor Statistics (2012). Economic News Release, June 01, Table B-1: Employees on nonfarm payrolls by industry sector and selected industry detail. URL:

Bongaarts, J. and Feeney, G. (1998). On the Quantum and Tempo of Fertility. Population and Development Review, Vol. 24(No. 2):271-291.

Bongaarts, J. and Sobotka, T. (2012). A Demographic Explanation for the Recent Rise in European Fertility. Population and Development Review, Vol. 38(No.1):83-120.

Cervellati, M. and Sunde, U. (2005). Human capital formation, life expectancy, and the process of development. American Economic Review, Vol. 95(No. 5):1653-1672.

Cervellati, M. and Sunde, U. (2011). Life expectancy and economic growth: the role of the demographic transition. Journal of Economic Growth, Vol. 16:99-133.

Cremieux P.-Y., Ouellette, P. and Pilon, C. (1999). Health care spending as determinants of heatth outcomes. Health Economics, Vol. 8:627-639.

Cutler, D. M., Deaton, A. and Lleras-Muney, A. (2006). The determinants of mortality. Journal of Economic Perspectives, Vol. 20: 97-120.

Dixit, A. K. and Stiglitz, J. E. (1977). Monopolistic competition and optimum product diversity. American Economic Review, Vol. 67(No. 3):297-308.

EUROSTAT (2012). Labour Force Survey. Employment by sex, age and detailed economic activity. URL: http://appsso.eurostat.ec.europa.eu/nui/show.do?dataset=lfsa_egan22d\&lang=en

Filmer, D. and Pritchett, L. (1999). The impact of public spending on health: does money matter? Social Science and Medicine, Vol. 49: 1309-1323.

Futagami, K. and Nakajima, T. (2001). Population aging and economic growth. Journal of Macroeconomics, Vol. 23(No. 1):31-44.

Fuchs, V.R. (2004). More variation in use of care, more flat-of-the-curve medicine. Why does it occur? What can be done about it? Health Affairs, Web Exclusive.

Grossman, G. M. and Helpman, E. (1991). Quality ladders in the theory of economic growth. Review of Economic Studies, Vol. 58(No. 1):43-61.

Hall, R. E. and Jones, C. I. (2007). The vlaue of life and the rise in health spending. Quarterly Journal of Economics, Vol. 122: 39-72. 
Hazan, M. (2009). Longevity and lifetime labor supply: evidence and implications. Econometrica, Vol. 77(No. 6):1829-1863.

Hazan, M. and Zoabi, H. (2006). Does longevity cause growth? A theoretical critique. Journal of Economic Growth, Vol. 11(No. 4):363-376.

Heijdra, B. J. and Mierau, J. O. (2011). The Individual Life Cycle and Economic Growth: An Essay on Demographic Macroeconomics. De Economist, Vol. 159(No. 1):63-87.

Heijdra, B. J. and van der Ploeg, F. (2002). Foundations of Modern Macroeconomics. Oxford University Press. Oxford.

Jones, C. I. (1995). R\&D-based models of economic growth. Journal of Political Economy, Vol. 103(No. 4):759-783.

Kalemli-Ozcan, S., Ryder, H. E., and Weil, D. (2000). Mortality decline, human capital investment, and economic growth. Journal of Development Economics, Vol. 62(No. 1):1-23.

Kelley, A. C. and Schmidt, R. M. (1995). Aggregate population and economic growth correlations: the role of the components of demographic change. Demography, Vol. 32(No. 4):543-555.

Kortum, S. (1997). Research, patenting and technological change. Econometrica, Vol. 65(No. 6):1389-1419.

Krueger, D. and Ludwig, A. (2007). On the consequences of demographic change for rates of returns on capital, and the distribution of wealth and welfare, Journal of Monetary Economics, Vol. 54:49-87.

Lichtenberg, F.R. (2004). Sources of U.S. longevity increase, 1960-2001. Quarterly Review of Economics and Finance, Vol. 44:369-389.

Lorentzen, P., McMillan, J., and Wacziarg, R. (2008). Death and development. Journal of Economic Growth, Vol. 13:81-124.

Lucas, R. E. (1988). On the mechanics of economic development. Journal of Monetary Economics, Vol. 22:3-42.

Miles, D. (1999). Modelling the impact of demographic change on the economy. Economic Journal, Vol. 109(No. 452):1-36.

Murphy, K. M. and Topel R. H. (2006). The value of health and longevity. Journal of Political Economy, Vol. 114:871-904.

Pauly, M. V. and Saxena, A. (2012). Health employment, medical spending, and long-term health reform. CES-Ifo Economic Studies, Vol. 58, No. 1: 49-72. 
Prettner, K. (2011). Population aging and endogenous economic growth. Program on the Global Demography of Aging Working Paper No. 72.

Prettner, K., Bloom, D., and Strulik, H. (Forthcoming). Declining fertility and economic well-being: do education and health ride to the rescue? Labour Economics.

Reinhart, V. R. (1999). Death and taxes: their implications for endogenous growth. Economics Letters, Vol 62(No 3):339-345.

Rivera, B. and Currais, L. (2004). Public health capital and productivity in the Spanish regions: a dynamic panel data model. World Development, Vol. 32 (No. 5): 871-885.

Romer, P. (1986). Increasing returns and long-run growth. Journal of Political Economy, Vol. 94(No. 5):1002-1037.

Romer, P. (1990). Endogenous technological change. Journal of Political Economy, 98(No. 5):71-102.

Saint-Paul, G. (1992). Fiscal policy in an endogenous growth model. Quarterly Journal of Economics, Vol. 107(No 4).

Schneider, M. T. and Winkler, R. (2010). Growth and welfare under endogenous lifetime. CER-ETH Economics Working Paper Series 10/13\%.

Shastry, G. K. and Weil, D. N. (2003). How much of cross-country income variation is explained by health? Journal of the European Economic Association, Vol. 1:387-396.

Suhrcke, M. and Urban, D. (2010). Are cardiovascular diseases bad for economic growth? Health Economics, Vol. 19:1478-1496.

Thornton, J. (2002). Estimating a health production function for the US: some new evidence. Applied Economics, Vol. 34:59-62.

van Zon, A. and Muysken, J. (2001). Health and endogenous growth. Journal of Health Economics, Vol. 20: 169-185.

Weil, D. (2007). Accounting for the effect of health on economic growth. The Quarterly Journal of Economics, Vol. 122(No. 3):1265-1306.

World Bank (2012). World Development Indicators \& Global Development Finance Database. URL: http://databank.worldbank.org/ddp/home.do?step=12\&id=4\&cno=2.

Yaari, M. E. (1965). Uncertain lifetime, life insurance and the theory of the consumer. The Review of Economic Studies, Vol. 32(No. 2):137-150. 


\section{Appendix}

\section{A Derivations}

\section{A.1 Relationship between Fertility and Mortality}

Our demographic assumptions imply that the size of the population at a given point in time is

$$
N(t)=N(-\infty) e^{(\beta-\mu) t}=\int_{-\infty}^{t} \beta N(-\infty) e^{\beta t_{0}} e^{-\mu t} d t_{0}
$$

where $\beta$ and $\mu$ are the period fertility and mortality rates, respectively and where $N(-\infty)$ denotes the size of the population at the origin. Let $m$ denote the number of children an individual desires to have over her life cycle (i.e., the cohort fertility). Then we have

$$
\begin{aligned}
m & =\int_{0}^{\infty} \beta e^{-\mu t} d t \\
& \Leftrightarrow \beta=\frac{m}{\int_{0}^{\infty} e^{-\mu t} d t}=\frac{m}{\left[-\mu^{-1} e^{-\mu t}\right]_{0}^{\infty}}=m \mu .
\end{aligned}
$$

Consequently,

$$
\frac{\partial \beta}{\partial \mu}=m
$$

But then in case of zero population growth, where $m=1$, we have that period fertility $\beta$ changes one to one in response to changes in $\mu$.

\section{A.2 The Individual Euler Equation}

The current value Hamiltonian is

$$
\mathbf{H}=\log (c)+\nu\left[(r+\mu-\delta) k+(1-\tau) w \ell+d-c-p_{H} \sigma h\right]
$$

with $\nu$ denoting the costate variable. The first order conditions are:

$$
\begin{aligned}
& \frac{1}{c}=\nu \\
& \dot{\nu}=(\rho+\delta-r) \nu .
\end{aligned}
$$

Taking the time derivative of (39) and plugging it into (40) yields

$$
\frac{\dot{c}}{c}=r-\rho-\delta,
$$

which is the individual Euler equation. 


\section{A.3 Aggregate Capital and Aggregate Consumption}

Differentiating (5) and (6) with respect to time yields

$$
\begin{aligned}
& \dot{C}(t)=\mu N c(t, t)-\mu C(t)+\mu N \int_{-\infty}^{t} \dot{c}\left(t_{0}, t\right) e^{-\mu\left(t-t_{0}\right)} d t_{0}, \\
& \dot{K}(t)=\mu N \underbrace{k(t, t)}_{=0}-\mu K(t)+\mu N \int_{-\infty}^{t} \dot{k}\left(t_{0}, t\right) e^{-\mu\left(t-t_{0}\right)} d t_{0} .
\end{aligned}
$$

Using (2) and (43) it follows that

$$
\begin{aligned}
\dot{K}(t) & =-\mu K(t) \\
& +\mu N \int_{-\infty}^{t}\left[(r+\mu-\delta) k\left(t_{0}, t\right)+(1-\tau) w(t) \ell+d(t)-c\left(t_{0}, t\right)-p_{H}(t) \sigma h\right] e^{-\mu\left(t-t_{0}\right)} d t_{0} \\
& =(r-\delta) K(t)-C(t)+(1-\tau) W(t)+D(t)+p_{H}(t) \sigma H
\end{aligned}
$$

which is the aggregate law of motion for capital with $W(t)=w(t) \ell N$ denoting aggregate wage income, $D(t)=d(t) N$ being aggregate dividend payments, and $H=h N$ denoting aggregate health consumption. Reformulating an agent's optimization problem subject to its lifetime budget restriction yields the optimization problem

$$
\begin{aligned}
\max _{c\left(t_{0}, \tau\right)} & U=\int_{t}^{\infty} e^{(\rho+\mu)(t-s)} \log \left(c\left(t_{0}, s\right)\right) d s \\
\text { s.t. } & k\left(t_{0}, t\right)+\int_{t}^{\infty}\left[(1-\tau) w(s) \ell+d(s)-p_{H} \sigma h\right] e^{-R^{A}(t, s)} d s=\int_{t}^{\infty} c\left(t_{0}, s\right) e^{-R^{A}(t, s)} d s,
\end{aligned}
$$

where $R^{A}(t, s)=\int_{t}^{s}(r(v)+\mu-\delta) d v$. The FOC is

$$
\frac{1}{c\left(t_{0}, s\right)} e^{(\rho+\mu)(t-s)}=\nu(t) e^{-R^{A}(t, s)} .
$$

In period $(s=t)$ we have

$$
c\left(t_{0}, t\right)=\frac{1}{\nu}
$$

Therefore we can write

$$
c\left(t_{0}, t\right) e^{(\rho+\mu)(t-s)}=c\left(t_{0}, s\right) e^{-R^{A}(t, s)} .
$$

Integrating and using the lifetime budget constraint given in the optimization problem (44) yields

$$
\begin{aligned}
\frac{c\left(t_{0}, t\right)}{\rho+\mu}\left[-e^{(\rho+\mu)(t-s)}\right]_{t}^{\infty} & =k\left(t_{0}, t\right)+\underbrace{\int_{t}^{\infty}\left[(1-\tau) w(s) \ell+d(s)-p_{H}(s) \sigma h\right] e^{-R^{A}(t, s)} d s}_{\omega(t)} \\
\Leftrightarrow c\left(t_{0}, t\right) & =(\rho+\mu)\left[k\left(t_{0}, t\right)+\omega(t)\right],
\end{aligned}
$$


where $\omega(t)$ refers to human wealth of individuals consisting of the lifetime income of wages and dividends net of taxes and private health care payments. Human wealth does not depend on the date of birth because of the assumed lump-sum nature of dividends and the assumption that productivity is age independent. Therefore, optimal consumption in the planning period is proportional to total wealth with a marginal propensity to consume of $\rho+\mu$. Aggregate consumption evolves according to

$$
\begin{aligned}
C(t) & =\mu N \int_{-\infty}^{t} e^{\mu\left(t_{0}-t\right)}(\rho+\mu)\left[k\left(t_{0}, t\right)+\omega(t)\right] d t_{0} \\
& =(\rho+\mu)[K(t)+\Omega(t)]
\end{aligned}
$$

where $\Omega(t)$ is aggregate human wealth. Note that newborns do not own capital because there are no bequests. Therefore

$$
c(t, t)=(\rho+\mu) \omega(t)
$$

holds for each newborn individual and each newborn cohort, respectively. Combining (41), (42), (46) and (47) yields

$$
\begin{aligned}
\dot{C}(t) & =[\mu(\rho+\mu) \Omega(t)-\mu(\rho+\mu)[K(t)+\Omega(t)]]+(r-\rho-\delta) C(t) \\
& \Leftrightarrow \frac{\dot{C}(t)}{C(t)}=r-\rho-\delta-\mu(\rho+\mu) \frac{K(t)}{C(t)}=r-\rho-\delta-\mu \frac{C(t)-c(t, t) N}{C(t)}
\end{aligned}
$$

which is the aggregate Euler equation that differs from the individual Euler equation by the term $-\mu[C(t)-c(t, t) N] / C(t) \in[-\mu, 0]$.

\section{A.4 Useful Relationships}

Using (17), (16), and (18) together with $K=A x$ we obtain

$$
\begin{aligned}
\pi & =\left(p_{i}-r\right) x=(1-\alpha) p_{i} x \\
& =(1-\alpha) \alpha L_{Y}^{1-\alpha} x^{\alpha}=\frac{(1-\alpha) \alpha Y}{A}
\end{aligned}
$$

Substituting into (23) then gives (24) as reported in Section 2.5.

Using (17), (16) and (18) together with $x=K / A$ we obtain

$$
\begin{aligned}
r & =\alpha p=\alpha^{2} \frac{Y}{K}, \\
& \Leftrightarrow \frac{Y}{K}=\frac{r}{\alpha^{2}} .
\end{aligned}
$$


Using (20), (21) and (25) we obtain

$$
w=p_{A} \lambda A=\frac{(1-\alpha) \alpha Y \lambda}{r-\delta} .
$$

From (13) we obtain

$$
\frac{G}{Y}=\frac{p_{H} \sigma H+\tau W}{Y}=\frac{(\sigma h+\tau \ell) w N}{Y}=\frac{[\sigma h+(1-\sigma) h] w N}{Y}=\frac{(1-\alpha) \alpha \lambda N h}{r-\delta},
$$

where the second equality follows when recalling that $p_{H}=w$ under perfect competition; where the third equality follows when recalling that $\tau=(1-\sigma) h / \ell$; and where the fourth equality follows when substituting from (51).

\section{A.5 Dynamics of the Aggregate Capital Stock}

We obtain the law of motion for the aggregate capital stock either from the goods market equilibrium $Y=C+I=C+\delta K+K$ or from the law of motion for aggregate wealth

$$
\begin{aligned}
\dot{K} & =(r-\delta) K+(1-\tau) W+D-C-p_{H} \sigma H \\
& =(r-\delta) K+[1-(1-\sigma) h / \ell] W+D-C-w \sigma H \\
& =(r-\delta) K+w\left(L_{A}+L_{Y}\right)+D-C \\
& =(r-\delta) K+w\left(L_{A}+L_{Y}\right)+A \pi-p_{A} \dot{A}-C \\
& =(r-\delta) K+w L_{Y}+A \pi-C \\
& =Y-\delta K-C
\end{aligned}
$$

where we observe $p_{H}=w, \tau=(1-\sigma) h / \ell$ and $[1-(1-\sigma) h / \ell] W-w \sigma H=w(1-h / \ell) L-$ $w \sigma h(N-L / \ell)=w\left(L_{A}+L_{Y}\right)$. Furthermore, dividends (net of new investment) are given by $D=A \pi-p_{A} \dot{A}$. Since $p_{A} \dot{A}=w L_{A}$ from (19) and (20), GDP then follows as $Y=r K+w L_{Y}+A \pi$, where $A \pi$ are aggregate rents paid to the monopolistic intermediate sector.

\section{A.6 Human Wealth}

Rewriting the definition of human wealth in (45) for a balanced groth path, we obtain

$$
\begin{aligned}
\omega(t) & =N^{-1} \int_{t}^{\infty}\left[(1-\tau) W(s)+D(s)-p_{H}(s) \sigma H\right] e^{-(r+\mu-\delta)(s-t)} d s \\
& =N^{-1} \int_{t}^{\infty}\left[w(s) L_{Y}(s)+A(s) \pi(s)\right] e^{-(r+\mu-\delta)(s-t)} d s \\
& =N^{-1} \int_{t}^{\infty}\left(1-\alpha^{2}\right) Y(s) e^{-(r+\mu-\delta)(s-t)} d s \\
& =N^{-1} \int_{t}^{\infty}\left(1-\alpha^{2}\right) Y(t) e^{-(r+\mu-\delta-g)(s-t)} d s,
\end{aligned}
$$


where the second equality follows in analogy to the calculation of $K$ in (53) (fifth line), where the third equality follows when substituting from (15) and (49), and where the last equality follows since $Y(s)=Y(t) e^{g(s-t)}$. Integrating out the last expression gives the second line in (35).

\section{B Proofs}

\section{B.1 Proof of Proposition 1}

Consider first, the case where $g>0$. Rewriting the equilibrium system (28)-(30) to

$$
\begin{aligned}
& X 1(r, \xi, g)=-\frac{r}{\alpha^{2}}+\xi+\delta+g=0, \\
& X 2(r, \xi, g)=-r+\rho+\delta+\frac{\mu(\rho+\mu)}{\xi}+g=0, \\
& X 3(r, \xi, g)=\lambda[\ell(h)-h] N-\frac{r-\delta}{\alpha}-g=0 .
\end{aligned}
$$

The determinant of the associated Jacobian is given by $\Delta:=-(1+\alpha) \alpha^{-2}\left(\alpha-X 2_{\xi}\right)<0$, where $X 2_{\xi}=-\mu(\rho+\mu) \xi^{-2}<0$. Together with the negative trace, this guarantees the existence of a unique and stable balanced growth path. Applying the implicit function theorem we obtain the comparative statics

$$
\begin{aligned}
\frac{d r}{d h} & =\frac{-\left[\left(1-X 2_{\xi}\right) \lambda\left(\ell^{\prime}-1\right) N+X 2_{h}\right]}{\Delta}, \\
\frac{d \xi}{d h} & =\frac{-(1+\alpha)\left[(1-\alpha) \lambda\left(\ell^{\prime}-1\right) N+X 2_{h}\right]}{\Delta \alpha^{2}}, \\
\frac{d g}{d h} & =\frac{-\left[\left(\alpha^{2}-X 2_{\xi}\right) \lambda\left(\ell^{\prime}-1\right) N-\alpha X 2_{h}\right]}{\Delta \alpha^{2}}
\end{aligned}
$$

with $X 2_{h}=\mu^{\prime}(\rho+2 \mu) \xi^{-1}<0$ and $X 2_{\xi}<0$ and $\Delta<0$ as given above. The signs of the derivatives reported in the Proposition can then be verified from (57)-(59). Furthermore, it is readily checked from (56) that we can equally write $d g / d h=\lambda\left(\ell^{\prime}-1\right) N-(1 / \alpha) d r / d h$ as reported in the Proposition.

Consider now, the case where $g=0$. In this case, the equilibrium is described by the system

$$
\begin{aligned}
& X 1(r, \xi, 0)=-\frac{r}{\alpha^{2}}+\xi+\delta=0, \\
& X 2(r, \xi, 0)=-r+\rho+\delta+\frac{\mu(\rho+\mu)}{\xi}=0,
\end{aligned}
$$

the determinant of which is given by $\Delta_{0}=1-\alpha^{-2} X 2_{\xi}>0$. Together with the negative trace, this guarantees the existence of a unique and stable equilibrium at $g=0$. For this 
case, we obtain the comparative statics

$$
\frac{d r}{d h}=\alpha^{2} \frac{d \xi}{d h}=\frac{X 2_{h}}{\Delta_{0}}<0 .
$$

\section{B.2 Proof of Proposition 2}

Define

$$
\begin{aligned}
\phi(h): & =\left(\alpha^{2}-X 2_{\xi}\right) \lambda\left(\ell^{\prime}-1\right) N-\alpha X 2_{h} \\
= & {\left[\alpha^{2}+\mu(\rho+\mu) \xi^{-2}\right] \lambda\left(\ell^{\prime}-1\right) N-\alpha \mu^{\prime}(\rho+2 \mu) \xi^{-1} . }
\end{aligned}
$$

For the case $h \in[\underline{h}, \bar{h}]$ with $g>0$, it is then readily verified from (59) that $d g / d h>0 \Leftrightarrow$ $\phi(h)>0$. Consider now $h \notin[\underline{h}, \bar{h}]$ implying that $X 3(r, \xi, 0)=\lambda[\ell(h)-h] N-(r-\delta) / \alpha \leq$ 0 . For this case, we obtain $d X 3(r, \xi, 0) / d h=\lambda\left(\ell^{\prime}-1\right) N-(1 / \alpha) d r / d h$. Inserting from (62) and rearranging terms, it is easy to verify that $d X 3(r, \xi, 0) / d h>0 \Leftrightarrow \phi(h)>0$.

In what follows we establish a set of properties of the function $\phi(h)$ allowing us to determine a unique level $\widehat{h}_{g} \in[\underline{h}, \bar{h}]$ for which the growth rate is maximized. Specifically, we will establish that $\phi(h)>0$ for $h \in\left[0, \widehat{h}_{g}\right)$ and $\phi(h)<0$ for $h \in\left(\widehat{h}_{g}, h_{\max }\right]$. While this implies the concavity of $g>0$ on the interval $[\underline{h}, \bar{h}]$, it also implies that an increase (decrease) in $h$ on the interval $\left[0, \underline{h}\right.$ ) (on the interval $\left(\bar{h}, h_{\max }\right]$ ) will eventually lead to $g>0$.

From (63) we obtain

$$
\begin{aligned}
\phi(0) & >0 \Leftrightarrow-\left.\mu^{\prime}\right|_{h=0}>Z(0) \lambda N\left(1-\left.\ell^{\prime}\right|_{h=0}\right) \\
\phi\left(h_{\max }\right) & <0 \Leftrightarrow-\left.\mu^{\prime}\right|_{h=h_{\max }}<Z\left(h_{\max }\right) \lambda N\left(1-\left.\ell^{\prime}\right|_{h=h_{\max }}\right),
\end{aligned}
$$

with

$$
Z(h):=\frac{\alpha^{2} \xi+\mu(\rho+\mu) \xi^{-1}}{\alpha(\rho+2 \mu)}
$$

implying the condition that $\left|\mu^{\prime}\right|_{h=0}$ be sufficiently large and $\left|\mu^{\prime}\right|_{h=h_{\max }}$ be sufficiently small, respectively. Consider the RHS in (64). First, as is readily verified, the expression is negative if $1 \leq\left.\ell^{\prime}\right|_{h=0}$, implying that the condition in (64) is satisfied for any $-\left.\mu^{\prime}\right|_{h=0}>0$.

Furthermore, it can be verified that $Z(0)$ is finite. This is evident for $\bar{\mu}<\infty$, as this also implies $\left.\xi\right|_{h=0} \in(0, \infty)$. Consider, thus, the limit $\bar{\mu} \rightarrow \infty$. First, we note that in this case the full equilibrium system (54)-(56) implies $\left.\lim _{\mu \rightarrow \infty} g\right|_{h=0}<0$. By contradiction, assume $\left.\lim _{\bar{\mu} \rightarrow \infty} g\right|_{h=0}>0$. From (56) this implies $\infty>\lambda N \geq \lambda \ell(0) N>\left(\left.\lim _{\mu \rightarrow \infty} r\right|_{h=0}-\delta\right) / \alpha$ and, therefore, $\left.\lim _{\bar{\mu} \rightarrow \infty} r\right|_{h=0}<\infty$. But then from (55) it must be true that $\left.\lim _{\bar{\mu} \rightarrow \infty} \xi\right|_{h=0}=\infty$, which together with $\left.\lim _{\bar{\mu} \rightarrow \infty} r\right|_{h=0}<\infty$ generates a contradiction in (54). We therefore need to consider the boundary solution with $\left.\lim _{\bar{\mu} \rightarrow \infty} g\right|_{h=0}=0$. Substituting now from (60) and 
(61) into (66) we obtain

$$
\lim _{\bar{\mu} \rightarrow \infty} Z(0)=\frac{\left.2 \lim _{\bar{\mu} \rightarrow \infty} r\right|_{h=0}-\left(1+\alpha^{2}\right) \delta-\rho}{\alpha(\rho+2 \bar{\mu})} .
$$

Now consider $\lim _{\bar{\mu} \rightarrow \infty} Z(0)$, where $\left.\lim _{\bar{\mu} \rightarrow \infty} r\right|_{h=0}=\infty$. Using l'Hospital's rule and observing (62) we obtain

$$
\begin{aligned}
\lim _{\bar{\mu} \rightarrow \infty} Z(0)= & \frac{2 \frac{\left.d r\right|_{h=0}}{d \bar{\mu}}}{2 \alpha}=\frac{1}{\alpha} \frac{(\rho+2 \bar{\mu})\left(\left.\lim _{\bar{\mu} \rightarrow \infty} \xi\right|_{h=0}\right)^{-1}}{1-\left.\alpha^{-2} \lim _{\bar{\mu} \rightarrow \infty} X 2_{\xi}\right|_{h=0}} \\
= & \frac{\alpha(\rho+2 \bar{\mu})\left(\left.\lim _{\bar{\mu} \rightarrow \infty} \xi\right|_{h=0}\right)^{-1}}{\alpha^{2}+\bar{\mu}(\rho+\bar{\mu})\left(\left.\lim _{\bar{\mu} \rightarrow \infty} \xi\right|_{h=0}\right)^{-2}}=\left(\lim _{\bar{\mu} \rightarrow \infty} Z(0)\right)^{-1}
\end{aligned}
$$

and, therefore, $\lim _{\mu \rightarrow \infty} Z(0)=1$, which is obviously finite.

Now consider the RHS in (65). Since $1>\left.\ell^{\prime}\right|_{h=h_{\max }}$, the inequality is always satisfied for $-\left.\mu^{\prime}\right|_{h=h_{\max }} \rightarrow 0$ if

$$
Z\left(h_{\max }\right)=\frac{\left.\alpha^{2} \xi\right|_{h=h_{\max }}+\underline{\mu}(\rho+\underline{\mu})\left(\left.\xi\right|_{h=h_{\max }}\right)^{-1}}{\alpha(\rho+2 \underline{\mu})}>0 .
$$

This is true as $\underline{\mu} \geq 0$ implies $\left.\xi\right|_{h=h_{\max }} \in(0,1)$.

Given $\phi(0)>0>\phi\left(h_{\max }\right)$, the continuity of $\phi(h)$ implies the existence of at least one root. From (63) we obtain the derivative

$$
\begin{aligned}
\phi^{\prime}(h)= & \left(\alpha^{2}-X 2_{\xi}\right) \lambda \ell^{\prime \prime} N-\alpha \mu^{\prime \prime}(\rho+2 \mu) \xi^{-1} \\
& -X 2_{h} \xi^{-1} \lambda\left(\ell^{\prime}-1\right) N-2 \alpha \xi^{-1}\left(\mu^{\prime}\right)^{2} \\
& +\left[2 X 2_{\xi} \lambda\left(\ell^{\prime}-1\right) N+\alpha X 2_{h}\right] \xi^{-1} \frac{d \xi}{d h},
\end{aligned}
$$

which generally cannot be signed without ambiguity. Evaluating this expression at some 
$\operatorname{root} \widehat{h}:=\arg _{h}\{\phi(h)=0\}$ we obtain

$$
\begin{aligned}
\phi^{\prime}(\widehat{h})= & \left(\alpha^{2}-X 2_{\xi}\right) \lambda \ell^{\prime \prime} N-\alpha \mu^{\prime \prime}(\rho+2 \mu) \xi^{-1} \\
& +X 2_{h} \xi^{-1} \lambda\left(\ell^{\prime}-1\right) N-2 \alpha \xi^{-1}\left(\mu^{\prime}\right)^{2} \\
& +\left.\left(\alpha^{2}+X 2_{\xi}\right) \xi^{-1} \lambda\left(\ell^{\prime}-1\right) N \frac{d \xi}{d h}\right|_{h=\widehat{h}} \\
= & \left(\alpha^{2}-X 2_{\xi}\right) \lambda \ell^{\prime \prime} N-\alpha \mu^{\prime \prime}(\rho+2 \mu) \xi^{-1} \\
& +X 2_{h} \xi^{-1} \lambda\left(\ell^{\prime}-1\right) N-2 \alpha \xi^{-1}\left(\mu^{\prime}\right)^{2} \\
& +\left(\alpha^{2}+X 2_{\xi}\right) \xi^{-1} \alpha^{-1}\left[\lambda\left(\ell^{\prime}-1\right) N\right]^{2} \\
= & \left(\alpha^{2}-X 2_{\xi}\right) \lambda \ell^{\prime \prime} N-\alpha \mu^{\prime \prime}(\rho+2 \mu) \xi^{-1} \\
& -2 \alpha \xi^{-1}\left\{\left(\mu^{\prime}\right)^{2}-\left[\lambda\left(\ell^{\prime}-1\right) N\right]^{2}\right\} \\
= & \alpha X 2_{h}^{-1}\left(\ell^{\prime}-1\right)^{-1} \ell^{\prime \prime}-\alpha \mu^{\prime \prime}(\rho+2 \mu) \xi^{-1} \\
& -2 \alpha \xi^{-1}\left\{\left(\mu^{\prime}\right)^{2}-\left[\lambda\left(\ell^{\prime}-1\right) N\right]^{2}\right\} \\
= & \frac{\alpha}{\xi\left(\ell^{\prime}-1\right)}\left\{\begin{array}{c}
(\rho+2 \mu)\left[\mu^{\prime} \ell^{\prime \prime}-\mu^{\prime \prime}\left(\ell^{\prime}-1\right)\right] \\
-2\left(\ell^{\prime}-1\right)\left\{\left(\mu^{\prime}\right)^{2}-\left[\lambda\left(\ell^{\prime}-1\right) N\right]^{2}\right\}
\end{array}\right\} .
\end{aligned}
$$

Here, the first equality follows from $\alpha X 2_{h}=\left(\alpha^{2}-X 2_{\xi}\right) \lambda\left(\ell^{\prime}-1\right) N$; the second equality follows when observing that $d \xi /\left.d h\right|_{h=\widehat{h}}=-\frac{\lambda\left(\ell^{\prime}-1\right) N}{\alpha}$; the third equality follows when observing that $X 2_{h} \xi^{-1} \lambda\left(\ell^{\prime}-1\right) N+\left(\alpha^{2}+X 2_{\xi}\right) \xi^{-1} \alpha^{-1}\left[\lambda\left(\ell^{\prime}-1\right) N\right]^{2}=$ $\left[\left(\alpha^{2}-X 2_{\xi}\right)+\left(\alpha^{2}+X 2_{\xi}\right)\right] \xi^{-1} \alpha^{-1}\left[\lambda\left(\ell^{\prime}-1\right) N\right]^{2}=\alpha \xi^{-1}\left[\lambda\left(\ell^{\prime}-1\right) N\right]^{2}$; the fourth equality follows when observing, again, that $\left(\alpha^{2}-X 2_{\xi}\right) \lambda N=\alpha X 2_{h}^{-1}\left(\ell^{\prime}-1\right)^{-1}$; and the final equality follows when using $X 2_{h}=\mu^{\prime}(\rho+2 \mu) \xi^{-1}$ and then collecting terms. ${ }^{26}$ We prove now that the assumptions (12) and (10) imply the existence of exactly one root $\widehat{h} \in(0,1)$ at which $\phi(\widehat{h})=0$ and $\phi^{\prime}(\widehat{h})<0$. We begin by noting that $\phi(0)>0>\phi\left(h_{\max }\right)$ implies an odd number of roots, $m \in\{1,3,5,7, \ldots\}$, where $\phi^{\prime}\left(\widehat{h}_{1}\right)<0$ and $\phi^{\prime}\left(\widehat{h}_{m}\right)<0$ must be true. We can now prove that $m=1$ by contradiction. Thus, suppose $m>1$ and consider the root $m-1$, with $\widehat{h}_{m-1}<\widehat{h}_{m}$. By construction, it must then be true that $\phi^{\prime}\left(\widehat{h}_{m-1}\right)>0$. Now define $\widehat{\phi}(\widehat{h}):=$ $(\rho+2 \mu)\left[\mu^{\prime} \ell^{\prime \prime}-\mu^{\prime \prime}\left(\ell^{\prime}-1\right)\right]-2\left(\ell^{\prime}-1\right)\left\{\left(\mu^{\prime}\right)^{2}-\left[\lambda\left(\ell^{\prime}-1\right) N\right]^{2}\right\}$ and observe from (67) that $\operatorname{sgn} \phi^{\prime}(\widehat{h})=-\operatorname{sgn} \widehat{\phi}(\widehat{h}) \cdot{ }^{27}$ Thus, $\phi^{\prime}\left(\widehat{h}_{m-1}\right)>0$ implies $\widehat{\phi}\left(\widehat{h}_{m-1}\right)<0$. Furthermore, we have $\widehat{\phi}^{\prime}=(\rho+2 \mu)\left[\mu^{\prime} \ell^{\prime \prime \prime}-\mu^{\prime \prime \prime}\left(\ell^{\prime}-1\right)\right]+6\left(\ell^{\prime}-1\right)\left[\ell^{\prime \prime}\left(\ell^{\prime}-1\right)(\lambda N)^{2}-\mu^{\prime} \mu^{\prime \prime}\right] \leq 0$ for any value $\widehat{h} \in\left[0, h_{\max }\right] .{ }^{28}$ Since $\widehat{h}_{m-1}<\widehat{h}_{m}$, it then follows that $\widehat{\phi}\left(\widehat{h}_{m-1}\right)<0$ implies

\footnotetext{
${ }^{26} d \xi /\left.d h\right|_{h=\widehat{h}}=-\lambda \psi(\widehat{h}) / \alpha$ is readily verified when noting from (63) that $X 2_{h}=$ $-\alpha^{-1}\left(\alpha^{2}-X 2_{\xi}\right) \lambda\left(\ell^{\prime}-1\right) N$ for $h=\widehat{h}$, substituting this into (58), and simplifying the resulting expression.

${ }^{27}$ Recall here that $\left.\ell^{\prime}\right|_{h=\widehat{h}}<1$.

${ }^{28}$ Note that by construction the function $\widehat{\phi}(\widehat{h})$ describes the sign of the first derivative $\phi^{\prime}(\widehat{h})$ with respect to $h$ when it is evaluated at a root $\widehat{h}$. The derivative $\widehat{\phi}^{\prime}(\widehat{h})$ with respect to $\widehat{h}$ describes how the
} 
$\widehat{\phi}\left(\widehat{h}_{m}\right)<0$, which contradicts $\phi^{\prime}\left(\widehat{h}_{m}\right)<0$. Thus, $m>1$ cannot be true, implying the existence of a unique root $\widehat{h}=\widehat{h}_{g}$. Maximization of the growth rate then follows immediately from the construction of $\phi(h)$.

The uniqueness of the root $\widehat{h}=\widehat{h}_{g}$ implies $\phi(h)>0$ for $h \in\left[0, \widehat{h}_{g}\right)$ and $\phi(h)<0$ for $h \in\left(\widehat{h}_{g}, h_{\max }\right]$. While this implies the concavity of $g>0$ on the interval $[\underline{h}, \bar{h}]$, it also rules out that $g>0$ on either $[0, \underline{h})$ or $\left(\bar{h}, h_{\max }\right]$. In turn, this implies the uniqueness of $\underline{h}$ and $\bar{h}$.

\section{B.3 Proof of Corollary 3}

Given that $\underline{h}=0$ the comparative static terms in (57)-(59), as reported in Appendix B.1, apply on the whole interval $[0, \bar{h})$. Then, observing $\left.\ell^{\prime}\right|_{h=0}>1$ and $\ell^{\prime \prime}<0$, the existence of $\widehat{h}_{\xi}=\widehat{h}_{r}=\widehat{h}_{g} \in(0, \bar{h})$ is readily established from (57)-(59) for $\mu^{\prime}=\mu^{\prime \prime}=0$. By continuity, the argument extends to $\mu^{\prime}<0 \leq \mu^{\prime \prime}$ but sufficiently low in absolute value. For this case, we note (i) that $\widehat{h}_{\xi}<\widehat{h}_{r}$ follows from $d \xi /\left.d h\right|_{h=\widehat{h}_{r}}<0$ and $d r /\left.d h\right|_{h=\widehat{h}_{\xi}}>0$, as is readily verified from (57) and (58); and (ii) that $\mu^{\prime}<0$ implies $\widehat{h}_{r}<\left.h\right|_{\ell^{\prime}=1}<\widehat{h}_{g}$.

\section{B.4 Proof of Proposition 3}

Substituting successively from (38) into (37) and then into (36) we obtain

$$
\begin{aligned}
\frac{d U\left(t_{0}, t\right)}{d h(0)}= & \frac{-\mu^{\prime}}{(\rho+\mu)^{2}}\left[\log c\left(t_{0}, t\right)+\frac{2(r-\rho-\delta)}{\rho+\mu}\right] \\
& +\frac{\mu^{\prime}}{(\rho+\mu)^{2}}+\frac{\Theta\left(t_{0}, t\right)}{(\rho+\mu) \chi}\left[(t+1) \frac{d g}{d h(0)}-\frac{d r}{d h(0)}-\mu^{\prime}\right] \\
& +\frac{1}{(\rho+\mu)^{2}} \frac{d r}{d h(0)},
\end{aligned}
$$

with

$$
\begin{aligned}
\Theta\left(t_{0}, t\right) & :=\frac{\omega(t)}{k\left(t_{0}, t\right)+\omega(t)} \in[0,1] \\
\chi \quad: \quad & r+\mu-\delta-g=(\rho+\mu)\left(1+\mu \xi^{-1}\right)
\end{aligned}
$$

where the second equality in the definition of $\chi$ follows from the balanced growth condition (55). Consider $\mu^{\prime}=0$. We then obtain from (68)

$$
\begin{aligned}
\frac{d U\left(t_{0}, t\right)}{d h(0)} & =\frac{\Theta\left(t_{0}, t\right)}{(\rho+\mu) \chi}\left[(t+1) \frac{d g}{d h(0)}-\frac{d r}{d h(0)}\right]+\frac{1}{(\rho+\mu)^{2}} \frac{d r}{d h(0)} \\
& =\frac{\Theta\left(t_{0}, t\right)}{(\rho+\mu) \chi}(t+1) \frac{d g}{d h(0)}-\frac{\Theta\left(t_{0}, t\right)(\rho+\mu)-\chi}{(\rho+\mu)^{2} \chi} \frac{d r}{d h(0)}
\end{aligned}
$$

sign prescribing function $\widehat{\phi}(\widehat{h})$ changes with the level of the root $\widehat{h}$. It should not be misread as being descriptive in any way of the second-order derivative $\phi^{\prime \prime}(\widehat{h})$ with respect to $h$ and evaluated at $\widehat{h}$. 
Noting that $\Theta\left(t_{0}, t\right)(\rho+\mu)-\chi \leq(\rho+\mu)-\chi=-\mu(\rho+\mu) / \xi \leq 0$, where the equality follows when inserting from (70), it is readily verified that $d U\left(t_{0}, t\right) / d h(0)>0$ if $d g / d h(0)>$ 0 and $d r / d h(0)>0$ and $d U\left(t_{0}, t\right) / d h(0)<0$ if $d g / d h(0)<0$ and $d r / d h(0)<0$. Recalling from Corollary 3 that $d g / d h(0) \geq 0 \Leftrightarrow d r / d h(0) \geq 0$, which in turn is true if and only if $h \leq \widehat{h}_{r}=\left.h\right|_{\ell^{\prime}=1}=\widehat{h}_{g}$ it follows that $d U\left(t_{0}, t\right) / d h(0) \geq 0 \Leftrightarrow h(0) \leq \widehat{h}_{g}$, implying that $d U\left(t_{0}, t\right) /\left.d h(0)\right|_{h(0)=\widehat{h}_{g}}=0$ describes a maximum.

\section{B.5 Proof of Lemma 1}

Consider $t_{0} \leq 0$ such that $k\left(t_{0}, 0\right) \geq 0$ in (69) and, therefore, $\Theta\left(t_{0}, 0\right) \leq 1$. Using (38) we can rearrange $(37)$ to

$$
\left.\frac{d c\left(t_{0}, 0\right)}{d h(0)}\right|_{h(0)=\widehat{h}_{g}}=c\left(t_{0}, 0\right)\left[\frac{\mu^{\prime}}{\rho+\mu}+\frac{\Theta\left(t_{0}, 0\right)}{\chi}\left(-\left.\frac{d r}{d h(0)}\right|_{h(0)=\widehat{h}_{g}}-\mu^{\prime}\right)\right] .
$$

Note that the RHS increases in $\Theta\left(t_{0}, 0\right)$ and that $d \Theta\left(t_{0}, 0\right) / d t_{0}=$ $\left[-\Theta\left(t_{0}, 0\right) /\left(k\left(t_{0}, 0\right)+\omega(t)\right)\right] d k\left(t_{0}, 0\right) / d t_{0}>0$ since $d k\left(t_{0}, 0\right) / d t_{0}<0$. It follows that $d c\left(t_{0}, 0\right) /\left.d h(0)\right|_{h(0)=\widehat{h}_{g}} \leq 0 \Leftrightarrow t_{0} \leq \widehat{t}_{0}$, where $\widehat{t}_{0}$ is implicitly defined by

$$
\Theta\left(\widehat{t}_{0}, 0\right)=\frac{\chi \mu^{\prime}}{(\rho+\mu)\left(\left.\frac{d r}{d h(0)}\right|_{h(0)=\widehat{h}_{g}}+\mu^{\prime}\right)} .
$$

From (57) and (59) we obtain after appropriate manipulations

$$
\left.\frac{d r}{d h(0)}\right|_{h(0)=\widehat{h}_{g}}=\frac{\mu^{\prime}(\rho+2 \mu)}{\xi} \frac{\alpha^{2} \xi^{2}}{\alpha^{2} \xi^{2}+\mu(\rho+\mu)}<0
$$

Using this, it follows immediately that $\Theta\left(\widehat{t}_{0}, 0\right) \geq 0$ and it can be shown after some manipulations that $\Theta\left(\widehat{t}_{0}, 0\right) \leq 1 \Leftrightarrow \mu \leq \alpha \xi$. Furthermore, $\Theta\left(\widehat{t}_{0}, 0\right) \in(0,1]$ implies that $\widehat{t}_{0} \in(-\infty, 0] .^{29}$ This completes the proof of part (i).

To prove part (ii) set $d g /\left.d h(0)\right|_{h(0)=\widehat{h}_{g}}=0$ in (68) and consider the differential

$$
\begin{aligned}
& \frac{d}{d t_{0}}\left(\left.\frac{d U\left(t_{0}, 0\right)}{d h(0)}\right|_{h(0)=\widehat{h}_{g}}\right) \\
& =\left[\frac{-\mu^{\prime}}{(\rho+\mu) c\left(t_{0}, 0\right)}+\frac{\Theta\left(t_{0}, 0\right)}{\chi c\left(t_{0}, 0\right)}\left(\left.\frac{d r}{d h(0)}\right|_{h(0)=\widehat{h}_{g}}+\mu^{\prime}\right)\right] \frac{d k\left(t_{0}, 0\right)}{d t_{0}}=0 \\
& \Leftrightarrow \Theta\left(t_{0}, 0\right)=\frac{\chi \mu^{\prime}}{(\rho+\mu)\left(\left.\frac{d r}{d h(0)}\right|_{h(0)=\widehat{h}_{g}}+\mu^{\prime}\right)}=\Theta\left(\widehat{t}_{0}, 0\right),
\end{aligned}
$$

where we observe that $d c\left(t_{0}, 0\right) / d t_{0}=(\rho+\mu) d k\left(t_{0}, 0\right) / d t_{0}<0$ and $d \Theta\left(t_{0}, 0\right) / d t_{0}=$ $\left[-(\rho+\mu) \Theta\left(t_{0}, 0\right) / c\left(t_{0}, 0\right)\right] d k\left(t_{0}, 0\right) / d t_{0}>0$. It can be verified that (72) implies a minimum so that $\widehat{t}_{0}:=\arg _{t_{0}<0} \min d U\left(t_{0}, 0\right) /\left.d h(0)\right|_{h(0)=\widehat{h}_{g}}$ is true.

\footnotetext{
${ }^{29}$ Note here that $k(-\infty, 0)=\infty$.
} 


\section{B.6 Proof of Proposition 4}

To prove part (i) we note that $k\left(t_{0}, t_{0}\right)=0$ in (69) and, therefore $\Theta\left(t_{0}, t_{0}\right)=1$ for $t_{0} \geq 0$. Employing this together with $d g /\left.d h(0)\right|_{h(0)=\widehat{h}_{g}}=0$ in (68) and collecting terms we obtain

$$
\begin{aligned}
\left.\frac{d U\left(t_{0}, t_{0}\right)}{d h(0)}\right|_{h(0)=\widehat{h}_{g}=} & \frac{-\mu^{\prime} \log c\left(t_{0}, t_{0}\right)}{(\rho+\mu)^{2}}+\frac{-\mu^{\prime}[2(r-\rho-\delta) \chi+(\rho+\mu)(\rho+\mu-\chi)]}{(\rho+\mu)^{3} \chi} \\
& -\left.\frac{\rho+\mu-\chi}{(\rho+\mu)^{2} \chi} \frac{d r}{d h(0)}\right|_{h(0)=\widehat{h}_{g}} .
\end{aligned}
$$

Inserting (71) and $\rho+\mu-\chi=-\mu(\rho+\mu) / \xi$ yields

$$
\left.\frac{d U\left(t_{0}, t_{0}\right)}{d h(0)}\right|_{h(0)=\widehat{h}_{g}}=\frac{-\mu^{\prime} \log c\left(t_{0}, t_{0}\right)}{(\rho+\mu)^{2}}+\frac{-\mu^{\prime} \Phi}{(\rho+\mu)^{3} \chi\left[\alpha^{2} \xi^{2}+\mu(\rho+\mu)\right]}
$$

with

$$
\begin{aligned}
\Phi= & 2(r-\rho-\delta) \chi\left[\alpha^{2} \xi^{2}+\mu(\rho+\mu)\right] \\
& -\mu(\rho+\mu)^{2} \xi^{-1}\left\{\left[\alpha^{2} \xi^{2}+\mu(\rho+\mu)\right]+\alpha^{2} \xi(\rho+2 \mu)\right\} \\
= & {\left[2(r-\rho-\delta) \chi-\mu(\rho+\mu)^{2} \xi^{-1}\right]\left[\alpha^{2} \xi^{2}+\mu(\rho+\mu)\right] } \\
& -\alpha^{2} \mu(\rho+\mu)^{2}(\rho+2 \mu) \\
= & (\rho+\mu)\left\{\left[2(r-\rho-\delta)\left(1+\mu \xi^{-1}\right)-\mu(\rho+\mu) \xi^{-1}\right]\left[\alpha^{2} \xi^{2}+\mu(\rho+\mu)\right]\right. \\
& \left.-\alpha^{2} \mu(\rho+\mu)(\rho+2 \mu)\right\} \\
= & (\rho+\mu)\left\{\left[2 g\left(1+\mu \xi^{-1}\right)+\mu(\rho+\mu) \xi^{-1}\left(1+2 \mu \xi^{-1}\right)\right]\left[\alpha^{2} \xi^{2}+\mu(\rho+\mu)\right]\right. \\
& \left.-\alpha^{2} \mu(\rho+\mu)(\rho+2 \mu)\right\} \\
= & (\rho+\mu)\left\{2 g\left(1+\mu \xi^{-1}\right)\left[\alpha^{2} \xi^{2}+\mu(\rho+\mu)\right]+\mu^{2}(\rho+\mu)^{2} \xi^{-2}(\xi+2 \mu)\right. \\
& \left.+\alpha^{2} \mu(\rho+\mu)(\xi-\rho)\right\}>0
\end{aligned}
$$

where the third equality follows after substituting from (70) and collecting terms; where the fourth equality follows after substituting from (55) and collecting terms; where the fifth equality follows after appropriate rearrangements; and where the inequality follows when observing that $\xi-\rho=r\left(1-\alpha^{2}\right) \alpha^{-2}+\mu(\rho+\mu) \xi^{-1}>0$ as from (54) and (55), implying that all terms in the bracelets are non-negative. But then, $d U\left(t_{0}, t_{0}\right) /\left.d h(0)\right|_{h(0)=\widehat{h}_{g}}>0$ if $\log c\left(t_{0}, t_{0}\right) \geq 0$, which completes the proof of part (i).

To prove part (ii) we recall from Lemma 1 that $d U\left(t_{0}, 0\right) /\left.d h(0)\right|_{h(0)=\widehat{h}_{g}} \geq$ $d U\left(\widehat{t}_{0}, 0\right) /\left.d h(0)\right|_{h(0)=\widehat{h}_{g}}$ for all $t_{0} \leq 0$. It is therefore necessary and sufficient to establish $d U\left(\widehat{t}_{0}, 0\right) /\left.d h(0)\right|_{h(0)=\widehat{h}_{g}} \geq 0$. Inserting from (72) into (68) we obtain

$$
\left.\frac{d U\left(\widehat{t}_{0}, 0\right)}{d h(0)}\right|_{h(0)=\widehat{h}_{g}}=\frac{-\mu^{\prime} \log c\left(\widehat{t}_{0}, 0\right)}{(\rho+\mu)^{2}}-\frac{2 \mu^{\prime}(r-\rho-\delta)}{(\rho+\mu)^{3}}+\left.\frac{1}{(\rho+\mu)^{2}} \frac{d r}{d h(0)}\right|_{h(0)=\widehat{h}_{g}} .
$$


For $\log c\left(\widehat{t}_{0}, 0\right)>\log c(0,0) \geq 0$ it follows that $d U\left(\widehat{t}_{0}, 0\right) /\left.d h(0)\right|_{h(0)=\widehat{h}_{g}} \geq 0$ if

$$
\begin{aligned}
& \left.\frac{d r}{d h(0)}\right|_{h(0)=\widehat{h}_{g}}-\frac{2 \mu^{\prime}(r-\rho-\delta)}{\rho+\mu} \\
= & \frac{-\mu^{\prime}\left\{2(r-\rho-\delta)\left[\alpha^{2} \xi^{2}+\mu(\rho+\mu)\right]-\alpha^{2} \xi(\rho+2 \mu)(\rho+\mu)\right\}}{(\rho+\mu)\left[\alpha^{2} \xi^{2}+\mu(\rho+\mu)\right]} \\
= & \frac{-\mu^{\prime}\left\{2\left[g+\mu(\rho+\mu) \xi^{-1}\right]\left[\alpha^{2} \xi^{2}+\mu(\rho+\mu)\right]-\alpha^{2} \xi(\rho+2 \mu)(\rho+\mu)\right\}}{(\rho+\mu)\left[\alpha^{2} \xi^{2}+\mu(\rho+\mu)\right]} \geq 0 \\
\Leftrightarrow & g \geq \frac{(\rho+\mu)\left[\alpha^{2} \xi^{2} \rho-2 \mu^{2}(\rho+\mu)\right]}{2 \xi\left[\alpha^{2} \xi^{2}+\mu(\rho+\mu)\right]}
\end{aligned}
$$

implying that the growth rate must be sufficiently large. Note that the condition is non-trivial by considering e.g. the limiting case $\mu \rightarrow 0$. The requirement is then given by $g \geq \rho^{2} /(2 \xi)$ and violated for $g=0$, the latter implying from (60) and (61) that $\xi=\left[\rho+\left(1-\alpha^{2}\right) \delta\right] / \alpha^{2}<\infty$. Hence, $g$ must be sufficiently large, which completes the proof of part (ii). 


\section{VIENNA INSTITUTE OF DEMOGRAPHY}

\section{Working Papers}

Sander, Nikola and Martin Bell, Age, Period and Cohort Effects on Migration of the Baby Boomers in Australia, VID Working Paper 05/2012.

Grafeneder-Weissteiner, Theresa, Ingrid Kubin, Klaus Prettner, Alexia Prskawetz, and Stefan Wrzaczek, Coping with Inefficiencies in a New Economic Geography Model, VID Working Paper 04/2012.

Goujon, Anne, Éric Caron Malenfant, and Vegard Skirbekk, Towards a Catholic North America? Projections of Religion in Canada and the US beyond the Mid-21st Century, VID Working Paper 03/2012.

Di Giulio, Paola, Christoph Bühler, Andreas Ette, Romina Fraboni, and Kerstin Ruckdeschel, Social Capital and Fertility Intentions: The Case of Italy, Bulgaria, and West Germany, VID Working Paper 02/2012.

Abel, Guy J., Estimating Global Migration Flow Tables Using Place of Birth Data, VID Working Paper 01/2012.

Ediev, Dalkhat M., At Modal Age at Death, the Hazard Rate is Determined by its Derivative, VID Working Paper 08/2011.

Zeman, Kryštof, Tomáš Sobotka, Richard Gisser, Maria Winkler-Dworak, and Wolfgang Lutz, Geburtenbarometer Vienna: Analysing Fertility Convergence between Vienna and Austria, VID Working Paper 07/2011 (English and German versions available).

Feichtinger Gustav, Michael Kuhn, Alexia Prskawetz, and Stefan Wrzaczek, The Reproductive Value as Part of the Shadow Price of Population, VID Working Paper 06/2011.

Barakat, Bilal, Time is Money: Could Deferred Graduate Retirement Finance Higher Education?, VID Working Paper 05/2011.

Riosmena, Fernando, Maria Winkler-Dworak, Alexia Prskawetz, and Gustav Feichtinger, The Impact of Policies Influencing the Demography of Age Structured Populations: Lessons from Academies of Science, VID Working Paper 04/2011.

Buber, Isabella and Katrin Fliegenschnee, Are you Ready for a Child? A Methodological Triangulation on Fertility Intentions in Austria, VID Working Paper 03/2011.

The Vienna Institute of Demography Working Paper Series receives only limited review. Views or opinions expressed herein are entirely those of the authors. 